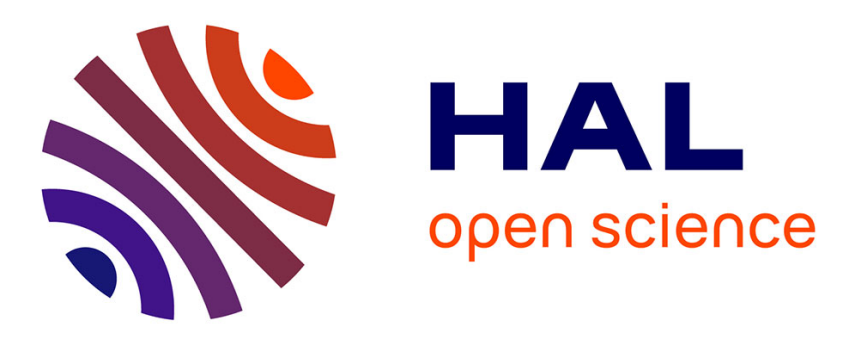

\title{
On the role of mRNA secondary structure in bacterial translation
}

Claude Chiaruttini, Maude Guillier

\section{To cite this version:}

Claude Chiaruttini, Maude Guillier. On the role of mRNA secondary structure in bacterial translation. Wiley Interdisciplinary Reviews: RNA, 2019, 11, 10.1002/wrna.1579 . hal-02383653

\section{HAL Id: hal-02383653 https://hal.science/hal-02383653}

Submitted on 18 Nov 2020

HAL is a multi-disciplinary open access archive for the deposit and dissemination of scientific research documents, whether they are published or not. The documents may come from teaching and research institutions in France or abroad, or from public or private research centers.
L'archive ouverte pluridisciplinaire HAL, est destinée au dépôt et à la diffusion de documents scientifiques de niveau recherche, publiés ou non, émanant des établissements d'enseignement et de recherche français ou étrangers, des laboratoires publics ou privés. 


\section{Article Title: On the role of mRNA secondary structure in bacterial translation}

\section{Article Type:}

ADVANCED REVIEW

4

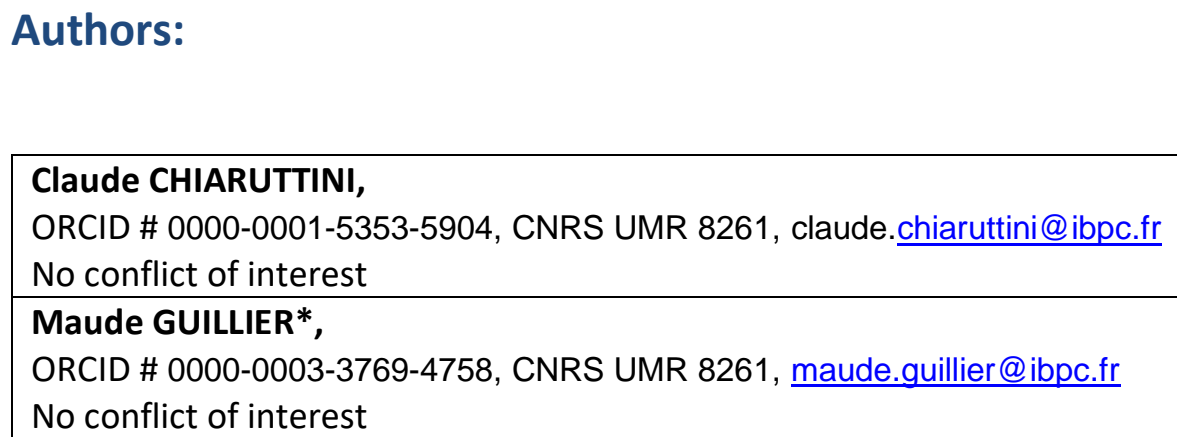

\section{Abstract}

Messenger RNA (mRNA) is no longer considered as a mere informational molecule whose sole function is to convey the genetic information specified by DNA to the ribosome. Beyond this primary function, mRNA also contains additional instructions that influence the way and the extent to which this message is translated by the ribosome into protein(s). Indeed, owing to its intrinsic propensity to quickly and dynamically fold and form higher order structures, mRNA exhibits a second layer of structural information specified by the sequence itself. Besides influencing transcription and mRNA stability, this additional information also affects translation, and more precisely the frequency of translation initiation, the choice of open reading frame by recoding, the elongation speed and the folding of the nascent protein. Many studies in bacteria have shown that mRNA secondary structure participates to the rapid adaptation of these versatile organisms to changing environmental conditions by efficiently tuning translation in response to diverse signals, such as the presence of ligands, regulatory proteins or small RNAs. 

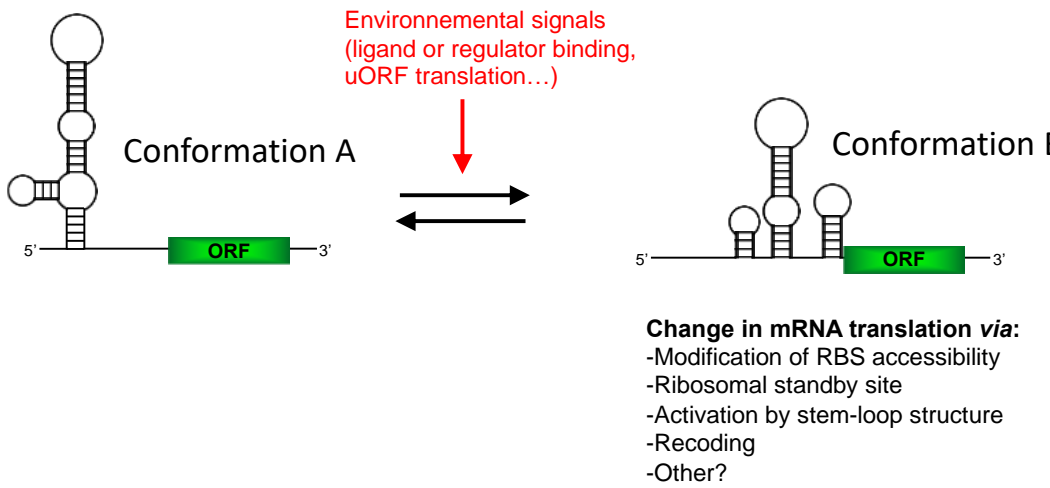

mRNA secondary structure influences translation in bacteria and plays a key role in the rapid adaptation of these organisms to their surroundings.

Introduction

Bacteria are versatile organisms that are able to rapidly adapt to environmental changes, which allows them to live in a wide range of different conditions. To this end, bacteria have a remarkable capacity to rapidly fine-tune their cellular composition by regulating the combined activities of the gene expression and quality control machineries. In particular, reshaping of the proteome occurs through many regulatory steps that can target transcription, mRNA translation and protein stability. By acting at a later step than transcription, especially during the initial phase of translation, posttranscriptional regulation may allow a faster adaptation than purely transcriptional events. Thus, in addition to being an essential step in gene expression, mRNA translation is also a key step in its control. All phases of translation, including initiation, elongation, termination, and ribosome recycling constitute checkpoints that can affect gene expression.

A large body of experimental evidence suggests that mRNA carries much more information than just the coding sequence that is translated into proteins by the ribosomes and the aminoacyl-tRNAs. In particular, RNA has the intrinsic propensity to dynamically fold and form higher order structures, such as stem-loops (Brion \& Westhof, 1997) or tertiary structures maintained by helical and/or unpaired motifs, such as pseudoknots (Batey, Rambo, \& Doudna, 1999; Pleij, Rietveld, \& Bosch, 1985) that are essential for its function. In mRNAs, a multitude of structural motifs determine the frequency of translation initiation (Gualerzi \& Pon, 2015), global and local elongation speeds (Wen et al., 2008; Plotkin \& Kudla, 2011; Chen et al., 2013), mRNA processing and degradation (Belasco, 2010; Nicholson, 2014; Briani, Carzaniga, \& Dehò, 2016) and folding of the nascent protein (Komar, 2009; G. Zhang, Hubalewska, \& Ignatova, 2009; G. Zhang \& Ignatova, 2011). In addition, since the pioneering work of 
Yanofsky and colleagues on transcriptional attenuation (Yanofsky, 2007), it has been widely accepted that alternative base pairing between mRNA segments plays a key role in the control of gene expression. Considering that RNA secondary structures tend to be highly dynamic and undergo conformational changes on a microsecond time scale (Crothers, Cole, Hilbers, \& Shulman, 1974; Pörschke, 1974), this is of great interest in terms of rapid mRNA conformational shifts and thereby efficient adaptation to changing environments.

A combination of recent advances in quantitative methods to study mRNA structures, abundance and translation on a genome-wide level in vivo, through biochemical, biophysical, genetic and bioinformatic approaches has confirmed the strong impact of mRNA secondary structure on translation efficiency and RNA stability or processing. In this review we will summarize our current knowledge, based on both single-gene studies and high-throughput approaches, on the role of mRNA secondary structure in modulating mRNA translation and in triggering specific translational events in bacteria. While secondary structure also clearly impacts mRNA stability and processing, this will not be discussed here as it is beyond the scope of this review.

\section{1. mRNA SECONDARY STRUCTURES AFFECT TRANSLATION INITIATION.}

In bacteria, translation initiation, that is the formation of a ternary complex in which the initiation codon of the mRNA translation initiation region (TIR) is decoded by the anticodon of the initiator fMettRNA in the P-site of the $30 \mathrm{~S}$ ribosomal subunit, is the limiting step of translation of most mRNAs. As such, initiation represents the target of the post-transcriptional regulation of a large number of bacterial genes and for this reason constitutes the step where the influence of mRNA structure on translation has been the most studied so far. Besides primary structure elements such as the initiation codon and the Shine-Dalgarno (SD) sequence present in most bacterial mRNAs (Gualerzi \& Pon, 2015) or AU-rich stretches acting as recognition/binding sites for the RNA helix-unwinding ribosomal protein S1 (Duval et al., 2013), secondary structure motifs contribute to shaping the TIR as the main variable in translation initiation. So far, studies aimed to determine the influence of mRNA structure on translation have shown that most mRNAs exhibit a lack of structure around the RBS and the start codon, supporting the view that access to the TIR by the ribosome is of crucial importance for translation initiation. However, and conversely, the TIR of other mRNAs exhibit a pronounced secondary structure which limits translation. For instance, a hairpin structure encompassing the RBS of the sigG mRNA encoding the late-acting sigma factor involved in Bacillus subtilis sporulation was recently found to keep sigG translation relatively low, which participates to the proper timing of sporulation (Mearls et al., 2018). Another example is provided by the structures that sequester the SD 
regions of multiple toxin genes that are present in bacterial chromosomes as part of toxin-antitoxin modules. By limiting toxin production, these structures are important to prevent toxicity (Masachis \& Darfeuille, 2018; Masachis et al., 2019). Furthermore, structural motifs are exploited by the cell to follow diverse strategies for regulation of translation initiation: they can either directly constitute the binding-site for regulators or build the structural scaffold required for adequate exposure of their binding-sites, or they can be modulated in response to diverse signals, such as temperature or $\mathrm{pH}$, or binding of regulatory ligands, such as RNAs, proteins or metabolites.

\subsection{Secondary structures mediate recognition and binding of mRNA by trans-acting regulators.}

\subsubsection{Secondary structure motifs form binding sites for regulatory proteins.}

Regulation at the post-transcriptional level by trans-acting proteins was one of the earliest forms of gene control discovered. A wide range of secondary structure motifs present in bacterial mRNAs have been shown to play key roles in the control of gene expression by trans-acting proteins. This is due to the fact that such structures constitute bona fide binding-sites for repressor proteins. In most cases, they sterically outcompete the binding of the $30 \mathrm{~S}$ ribosomal subunit to the ribosome binding site (RBS) (Figure 1). Two good examples of this simple regulatory mechanism are illustrated by the autoregulatory ribosomal proteins S8 and L20 of Escherichia coli (Cerretti, Mattheakis, Kearney, Vu, \& Nomura, 1988; Gregory, Cahill, Thurlow, \& Zimmermann, 1988; Guillier et al., 2002; Merianos, Wang, \& Moore, 2004; Mangeol et al., 2011). A different mechanism is used by the repressor ribosomal proteins S4 and S15 of $E$. coli that decrease translation initiation of their own mRNAs by trapping the 30 S ribosomal subunit in an inactive complex (Philippe et al., 1993; Spedding \& Draper, 1993).

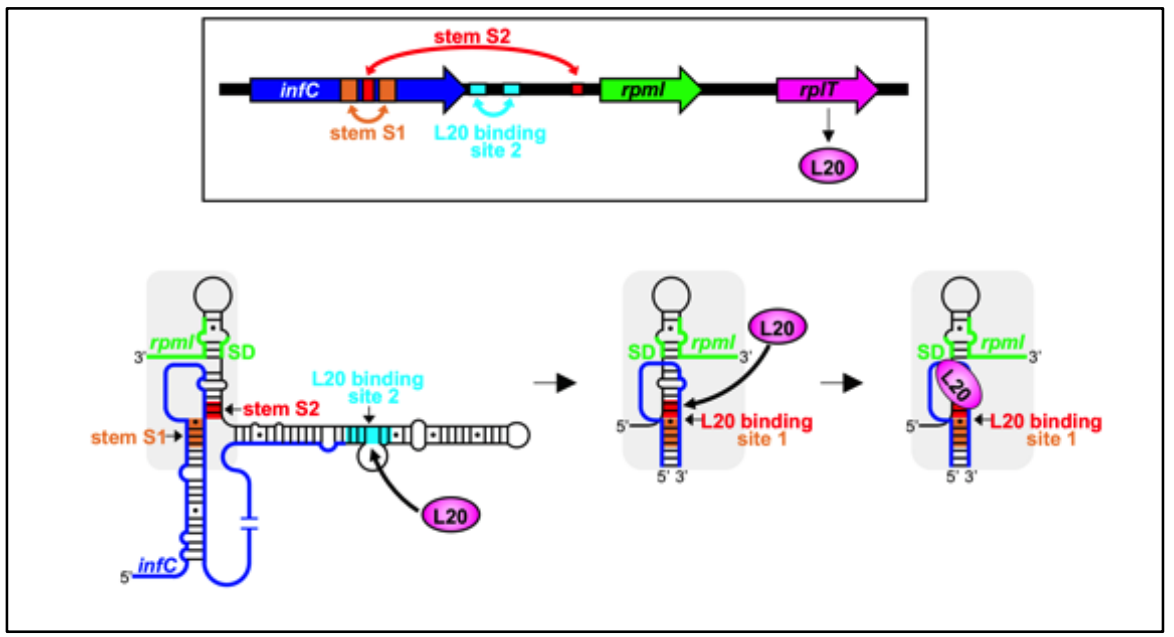

Figure 1. Schematic view of the two binding sites for repressor ribosomal protein $\mathrm{L} 20$ in the polycistronic infC-rpmI-rplT mRNA of E. coli. (Top) Schematic drawing of the mRNA. The infC, rpmI and rplT sequences are indicated by blue, green and purple arrows, respectively. Untranslated and intergenic sequences are colored in black. The sequences required for L20 binding are colored in orange for stem S1, red for stem S2 and cyan for L20-binding site 2. Double-headed arrows indicate base-pairing interactions. (Bottom left) Schematic 
drawing of the secondary structure of the mRNA region containing the sequences forming the two L20-binding sites. Stems S1 and S2 and L20-binding site 2 are colored as indicated above. Sequences forming the pseudoknotted L20-binding site 1 are boxed in gray. (Bottom middle) L20-binding site 1 is formed by stacking of stem S2 on stem S1. (Bottom right) Scheme of L20-bound site 1 complex.

99

100

101

102

103

104

105

106

107

108

109

110

111

112

113

114

115

116

117

118

119

120

121

In other cases, secondary structures act in conjunction with sequence determinants for binding a specific protein regulator. This has been reported for the CsrA protein and its homologues RsmA and RsmE that bind to multiple GGA motifs of mRNAs and typically repress translation by outcompeting with binding of the 30 S ribosomal subunit (reviewed in (Babitzke, Lai, Renda, \& Romeo, 2019)). Many CsrA binding-sites are also present in several regulatory RNAs, allowing to titrate the protein when these RNAs are expressed. A transcriptome-wide analysis of CsrA targets confirmed that the consensus sequence for CsrA binding is preferentially located in the apical loop of hairpins, highlighting the role of RNA structure in exposing RNA sequences (Holmqvist et al., 2016).

\subsubsection{Secondary structures shape mRNA scaffolds for proper recognition and binding by regulatory small RNAs.}

RNA secondary stuctures also play a key role in mediating control by another class of major posttranscriptional regulators in bacteria, the small RNAs (sRNAs). Regulation by sRNAs most often relies on sequence complementarity between the sRNA and its target-mRNA(s) and, again, it is well established that the structures of both the SRNA and the mRNA participate in the correct presentation of the pairing regions. Indeed, complementary sequences in both mRNA and sRNA are only functional when embedded in scaffolds that ensure they are mutually accessible. Early studies on antisense RNAs involved in the control of plasmid copy number highlighted the role of 'kissing' loops in RNA-RNA interactions, where the interacting regions of each RNA are found in the apical loops of helical structures (Figure 2). Following this initial kissing, a more extended and stable base-pairing interaction can take place such as a four-way junction in the case of E. coli copA-copT mRNA (Kolb et al., 2000; Wagner, Altuvia, \& Romby, 2002). 


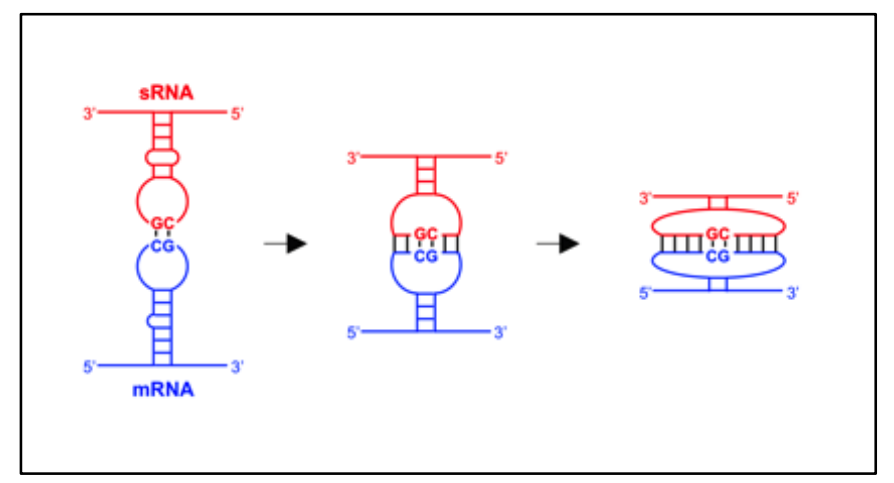

Figure 2. Schematic representation of a loop-loop interaction ('kissing)' between a sRNA and its target mRNA. A loop-loop interaction (here two GC base pairs) between the sRNA (in red) and its target mRNA (in blue) initiates the formation of a helix nucleus. The nascent helix grows by addition of base pairs in both directions.

Not surprisingly, the importance of accessible pairing sites is also true for sRNAs with only partial complementarity to their targets, where sequences in loops or unstructured, often $5^{\prime}$-terminal regions, can be used for pairing (e.g.(Papenfort, Bouvier, Mika, Sharma, \& Vogel, 2010; Romilly et al., 2012). In line with this, taking into account the accessibility of pairing-sites significantly improved the computational prediction of sRNA targets and RNA-RNA interactions (Beisel, Updegrove, Janson, \& Storz, 2012; Busch, Richter, \& Backofen, 2008; Mann, Wright, \& Backofen, 2017; Miladi, Montaseri, Backofen, \& Raden, 2018).

\subsection{Folding/unfolding of an mRNA secondary structure sequestering the RBS modulates its} accessibility to the ribosome.

\subsection{1 mRNA secondary structures act as temperature-sensing devices for temperature-dependent} gene expression (RNA thermometers).

The translation of several mRNAs whose TIRs encompass secondary structures around the RBS was found to be dependent on temperature, explained by the unfolding of RNA secondary structures to an open state at higher temperatures (Figure 3). These structures, known as RNA thermometers provide mRNAs with the ability to respond very rapidly to temperature shifts, because they control the translation of already existing or nascent mRNAs (Kortmann \& Narberhaus, 2012). The existence of an RNA thermometer was first reported for the mRNA encoding the heat-shock alternative sigma factor RpoH in E. coli (Morita et al., 1999), where the formation of a secondary structure that hinders the RBS accessibility was found to be partially impaired when temperature increases. This results in unmasking of the RBS and activation of translation initiation, allowing synthesis of heat-shock proteins. Similar RNA thermometers were later found in other heat-shock response genes in diverse bacteria, but also in virulence genes of several pathogens (Loh, Righetti, Eichner, Twittenhoff, \& Narberhaus, 2018). For instance, translation of the mRNA encoding the PrfA master virulence regulator of Listeria monocytogenes is up-regulated when temperature shifts from $30^{\circ}$ to $37^{\circ} \mathrm{C}$ via the 
melting of such a thermosensor, allowing expression of virulence genes in the host (Johansson et al., 2002). In both cases, an increase in temperature gradually shifts the equilibrium between the closed and open form of the RNA thermometer towards the open structure, in a zipper-like manner. The presence of such RNA thermometers in mRNAs illustrates a specific strategy that has evolved in bacteria to regulate the expression of temperature-dependent genes like those encoding virulence factors, heat shock and cold shock proteins (Kortmann and Narberhaus, 2012).

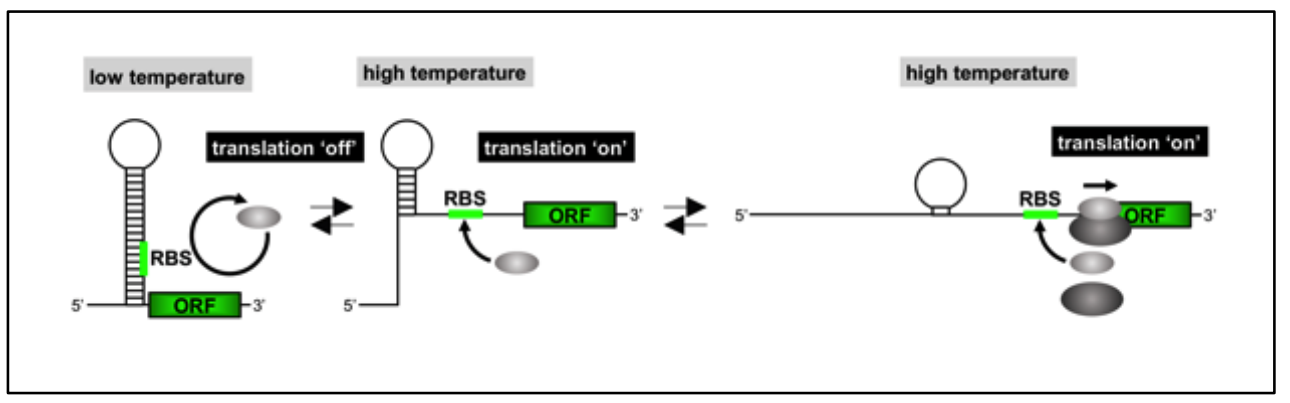

Figure 3. Mechanism of translation initiation control by environmental cues. An RNA thermometer (RNAT) is depicted in equilibrium between closed and open state. (Left) At low temperature, RNAT is closed and the RBS is masked, thus precluding 30S ribosomal subunit (in light gray) access to the mRNA (translation “off') (Middle and right) As temperature increases, RNAT gradually melts and opens, making the RBS more accessible to the subunit (translation "on") thus allowing translation to proceed upon binding of the 50S ribosomal subunit (in deep gray).

\subsubsection{Secondary structures of $m R N A$ act as translational coupling devices in the translation of} polycistronic mRNAs.

In addition to environmental cues such as temperature, translating ribosomes themselves can disrupt mRNA secondary structures that mask the RBS of downstream genes, allowing initiation of their translation. Control of gene expression in the E. coli IF3 operon illustrates how two secondary structure motifs in a polycistronic mRNA, a long irregular stem-loop and a stem-loop involved in pseudoknot formation, mediate translational coupling, albeit using distinct molecular mechanisms. The E. coli IF3 operon contains three cistrons, infC, $r p m /$ and $r p / T$, encoding translation initiation factor 3 and ribosomal proteins L35 and L20, respectively, in that order (see inset in Figure 1). The expression of $r p m /$ and $r p / T$ is controlled at the translational level by L20, which directly represses the expression of rpml and indirectly that of its own gene via translational coupling (Lesage, Truong, Graffe, Dondon, \& Springer, 1990). Coupling of $r p / T$ expression to that of $r p m /$ is governed by an inhibitory mRNA stemloop structure formed by base-pairing interactions between the $3^{\prime}$-terminal region of the $\mathrm{rpm} /$ coding sequence and the RBS of $r p / T$ (Lesage et al., 1992). Disruption of this inhibitory stem-loop by ribosomes translating $r p m /$ mRNA results in unmasking of the $r p / T$ RBS, which becomes accessible to incoming $30 S$ ribosomal subunit and initiator tRNA according to the standard model of bacterial translation initiation (Figure 4). Alternatively, it cannot be excluded that the 705 ribosome completing rpml translation could scan the sequence surrounding the stop codon of $r p m /$ for the presence of a nearby 


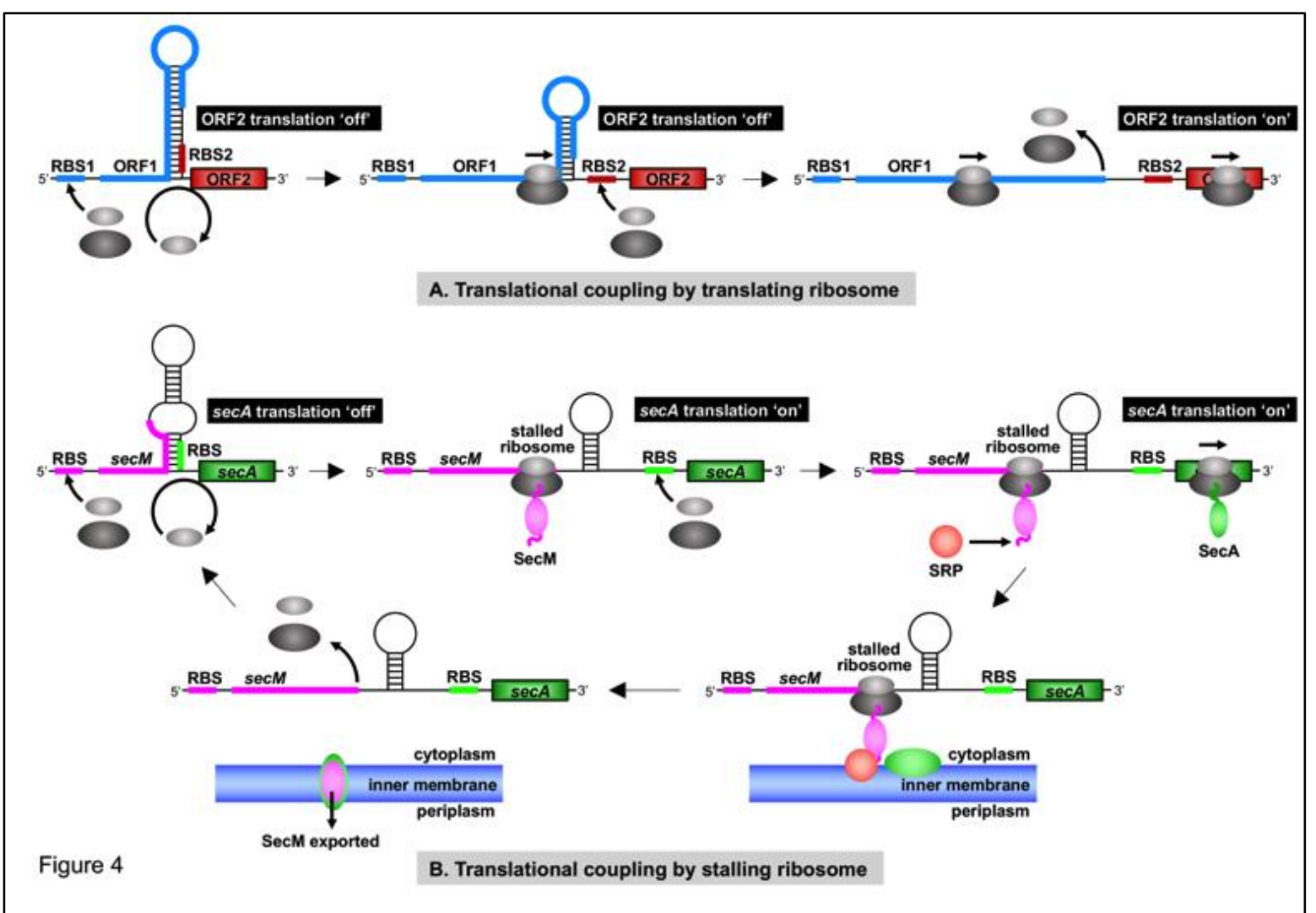

Figure 4. Mechanism of translation initiation activation by translational coupling. $(A)$ Coupling by a translating ribosome. When ORF 1 is not translated by ribosomes (left), the RBS of ORF2 is masked within a stem-loop structure by base pairing with an anti-RBS sequence located within ORF1. As a result, 30S ribosomal subunit access to the mRNA is blocked (translation "off"). When ORF1 is translated (middle and right), the translating ribosome progressively opens the inhibitory secondary structure. As a result, the RBS of ORF2 becomes accessible to an incoming 30S ribosomal subunit (translation "on"). (B) Translational coupling of sec $M$ and secA expression by ribosome stalling on secM mRNA. When secM is not translated (upper left), the $\sec A$ SD sequence is occluded in a stem-loop structure formed by the 3'-terminus of secM and the $\sec M$-secA intergenic region, leading to low initiation frequency of secA translation. When secM is translated, a ribosome stalls transiently at Pro166, located 12 nucleotides upstream of the stop codon (upper middle). During the time window of ribosome stalling, the stem-loop is disrupted and the secA SD sequence becomes accessible to incoming 30S ribosomal subunit. SRP binds to the peptide signal of SecM and co-translationally conveys the translating complex formed by the mRNA and the stalled ribosome tethered to the nascent SecM polypeptide to the membrane (lower right). As a result, SecA is synthesized close to the membrane where it assembles to the SecYEG channel to form the translocon. The secM translation arrest due to ribosome stalling is relieved by the mechanical 'pulling force' provided by the SecA-driven export of SecM from the cytoplasm to the periplasm through the translocon. As a result, SecM is dislodged from the translating complex (lower left) which in turn dissociates thus allowing reformation of the inhibitory stem-loop as the mRNA detaches from the ribosome (upper left). Consequently, duration of ribosome stalling, and thus induction of SecA synthesis, increases when SecM export is inhibited. 

secondary structure motif as well, but it proceeds via a more complicated mechanism than that evoked for $r p / T$. Translation of $r p m l$ is governed by a pseudoknot formed between a stem-loop within the infC coding region and a second sequence located far downstream that contains part of the RBS of rpmI (Figure 1) (Chiaruttini, Milet, \& Springer, 1996). Translation of IF3 necessarily first disrupts the stem-loop and then the long range interaction with the $r p m /$ RBS (Chiaruttini, Milet, \& Springer, 1997). Importantly, in addition to masking the $r p m /$ RBS, the pseudoknot has a second function as a binding site for L20, encoded by rplT (Guillier et al., 2002). Interestingly, L20 stabilizes the pseudoknot but does not accelerate its formation, as shown in an in vitro study based on the use of optical tweezers (Mangeol et al., 2011). As a consequence of pseudoknot disruption, not only is the rpm/ RBS unmasked but the binding of L20 is also impeded, resulting both in derepression of rpml and in turn that of $r p / T$. This is a clear illustration of how ribosome-driven disruption of an mRNA secondary structure involved in a tertiary interaction such as a pseudoknot can affect translation initiation of a downstream gene.

A more sophisticated mechanism of translational coupling governs the control of translation of the secA gene, encoding the protein translocation ATPase of $E$. coli. It has been shown that translation of secA depends on that of the previous cistron, called secM (for secA modulation or secretion monitor) (Murakami, Nakatogawa, \& Ito, 2004; Nakatogawa, Murakami, \& Ito, 2004). Coupling is governed by a secondary structure formed by a base pairing interaction between the end of the secM coding region and the secA RBS (Figure 4B). Importantly, the sequence of the SecM polypeptide between Phe150 and Pro166 causes the ribosome to stall transiently on mRNA. This stalling allows the unfolding of the secondary structure by translating ribosomes and a basal level of secA translation. Defects in exporting the SecM protein to the periplasm increase the stalling of the ribosomes and thereby ensure an upregulated synthesis of the SecA protein under these conditions. Hence, the duration of pausing, i.e. the time that the repressive secondary structure is not formed, is feedback-controlled by the rate at which the nascent SecM is secreted, which in turn depends on its signal peptide and interaction with SecA and the translocon (Sarker \& Oliver, 2002).

\subsection{An interplay between mutually exclusive mRNA secondary structures modulates ribosome} access to the RBS.

Changes in RBS accessibility can also arise from the establishment of alternative secondary structures in the vicinity of the RBS and other regions of the mRNA. Examples for this include translational attenuation, as well as control of gene expression by riboswitches acting at the 
translational level, or by trans-acting factors whose binding induces a structural remodeling of their target mRNAs.

1.3.1. A conformational switch between alternative $m R N A$ secondary structures induced by ribosomes translating a leader peptide affects translation initiation (translational attenuation).

Conversely to the mechanism at work in translational coupling, where disruption of an upstream inhibitory secondary structure by the ribosome activates the translation of a gene located downstream (see above), it was found that translation of several bacterial genes involved in resistance to antibiotics (e.g. erythromycin or chloramphenicol) depends on blocking the translation of a short upstream ORF (uORF), that expresses a leader peptide (Horinouchi \& Weisblum, 1980; Dubnau, 1985; Lovett, 1996). Ribosome stalling during translation of the uORF allows the mRNA to fold into a conformation favorable for translation of the downstream gene by exposing its RBS via the formation of alternative secondary structure motifs (Figure 5). Remarkably, stalling depends not only on the sequence of the leader peptide but also on binding of the cognate antibiotic to the ribosome, thereby inducing expression of antibiotic resistance genes only in its presence. By analogy to ribosomemediated transcriptional attenuation, where ribosome stalling at uORFs controls transcription termination by modulating mRNA structure via the formation of alternative stem-loops (Landick, Carey, \& Yanofsky, 1987), this mode of regulation is sometimes referred to as "translational attenuation".

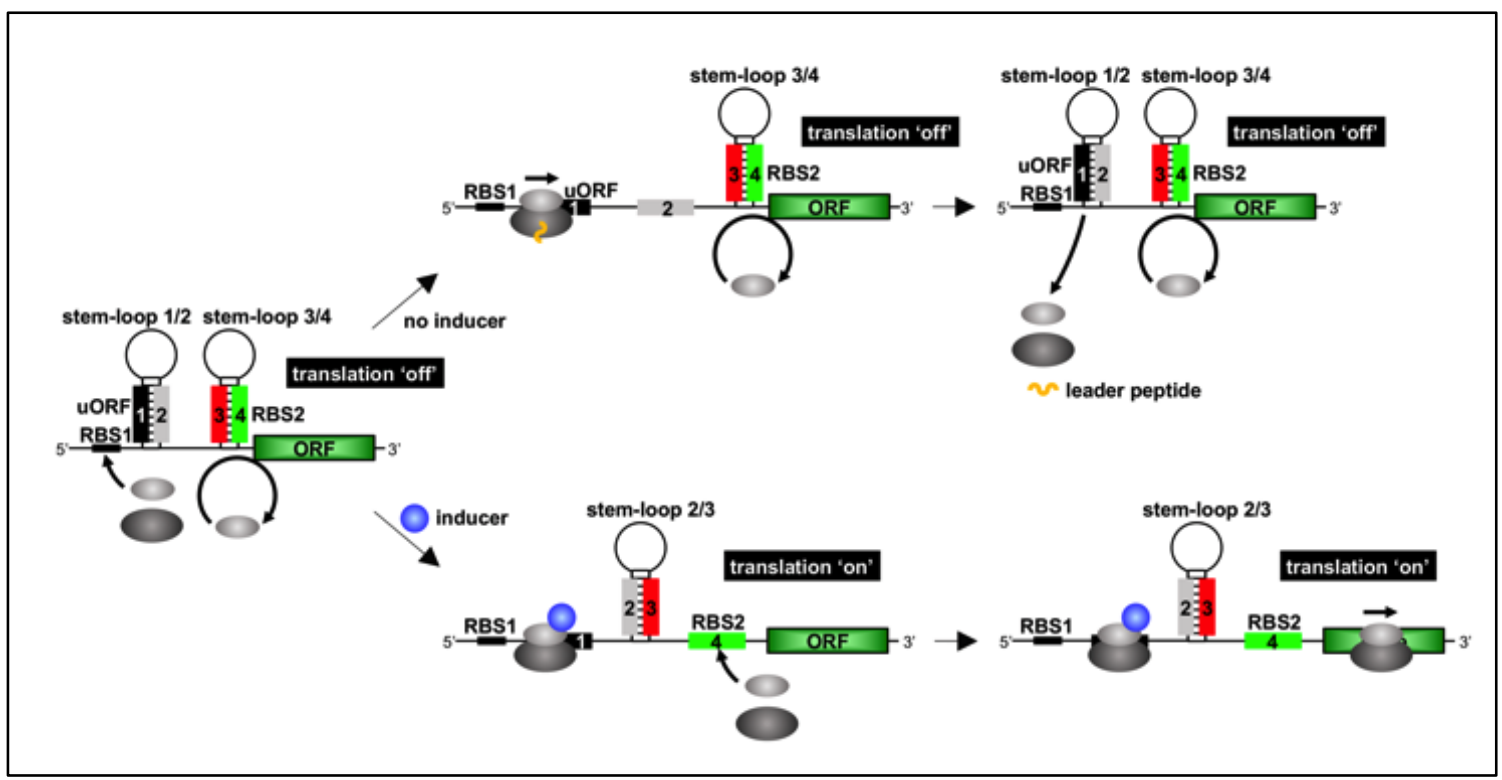

Figure 5. Control of translation initiation via rearrangement of mRNA secondary structure induced by ribosomes stalling on an upstream ORF (uORF). (Left and top left) In the absence of inducer, the $30 \mathrm{~S}$ ribosomal subunit binds to RBS1, promoting synthesis of a leader peptide (in orange) from uORF by the ribosome. Stem-loop 1/2 is transiently unwound, while RBS2 is occluded within stem 3/4 and is not accessible to 30S ribosomal subunit (translation “off”). (Top right) Stem-loop 1/2 reforms once the ribosome has passed through, while RBS2 remains occluded within stem-loop 3/4 (translation“off”). (Bottom left) In the presence 
of inducer, the inducer-bound ribosome stalls on uORF, triggering a structural switch by which disruption of stem-loop 1/2 leads to formation of alternative stem-loop 2/3 and consecutive unmasking of RBS2. (Bottom right) Binding of the $30 \mathrm{~S}$ ribosomal subunit to RBS2 allows translation of the ORF to proceed (translation "on").

More recently, it was found that ketolides, the newest generation of macrolides, could activate expression of the ermC gene involved in macrolide resistance, even though they failed to promote ribosome stalling in the UORF. Instead, ketolides induced a ribosomal frameshift during translation of the UORF, resulting in translating ribosomes by-passing the UORF stop codon and thus covering the intergenic region between the UORF and ermC. This prevented formation of the inhibitory structure for ermC expression via a different molecular mechanism than ribosome stalling (Gupta, Kannan, Mankin, \& Vázquez-Laslop, 2013) and references therein).

1.3.2. A conformational switch between alternative secondary structures is an essential feature of $m R N A$ riboswitches controlling translation initiation.

Several mRNA riboswitches control translation initiation through an allosteric conformational switch of the TIR caused by ligand binding to an aptamer domain (Figure 6). Depending on whether or not the aptamer domain is bound by a ligand, the structure of TIR is shaped by mutually exclusive secondary structures that can switch translation on or off. Riboswitch-control of translation was first reported in E. coli with the binding of thiamine and adenosylcobalamin leading to conformational switches in the thiM and btuB mRNAs encoding an enzyme involved in vitamin B1 biosynthesis and for the outer membrane protein responsible for vitamin B12 transport, respectively (Nahvi et al., 2002; Nou \& Kadner, 2000; Tucker \& Breaker, 2005; Winkler, Nahvi, \& Breaker, 2002). In both cases structural changes resulted in sequestration of the RBS and limited translation in presence of their cognate ligands (Figure 6A). 


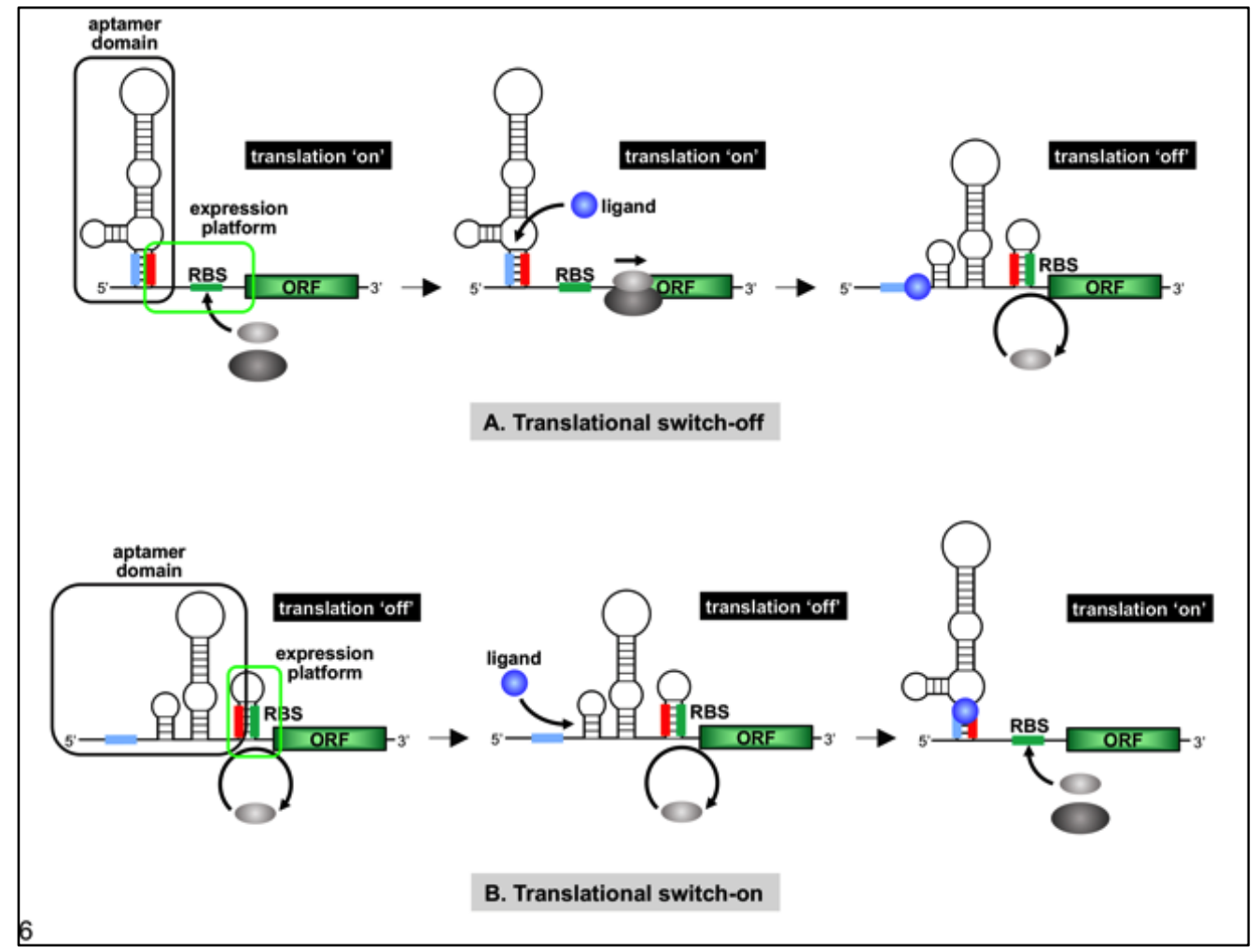

Figure 6. Mechanism of riboswitch-mediated control of translation initiation. A riboswitch is composed of an aptamer domain (outlined in black) that binds a small ligand and an expression platform (outlined in green) that controls gene expression. (A) (Left) In the absence of the ligand, an anti-RBS sequence (in red) is trapped in a secondary structure by pairing with an anti-anti-RBS sequence (in blue). (Middle) In this configuration, the RBS of the ORF (in green) is accessible to the $30 \mathrm{~S}$ ribosomal subunit (in light gray) and translation is allowed to proceed (translation "on") upon binding of the 50 S ribosomal subunit (in deep gray). (Right) When bound to the aptamer domain, the ligand promotes and stabilizes the formation of an alternative structure where an anti-RBS sequence pairs with the RBS thus preventing the binding of the $30 \mathrm{~S}$ ribosomal subunit (translation "off"). (B) (Left and middle) When the ligand is not bound to the aptamer domain, the RBS (in green) is trapped in a stem-loop by pairing with an anti-RBS sequence (in red), which prevents $30 \mathrm{~S}$ ribosomal subunit binding (translation "off”). (Right) Binding of the ligand induces a conformational switch by which the anti-SD sequence is trapped by an anti-anti-RBS sequence (in blue). The RBS becomes accessible to 30 S ribosomal subunit, thus leading to activation of translation initiation (translation "on").

Riboswitch-dependent control of gene expression can also proceed through activation of translation initiation upon unmasking of the RBS (Figure 6B). This is the case for the adenine-sensing riboswitch located in the 5'UTR of the add mRNA, encoding adenosine deaminase involved in purine catabolism in the Gram-negative bacterium Vibrio vulnificus (Rieder, Lang, Graber, \& Micura, 2007; Lemay et al., 2011). Although transcription and translation are coupled in bacteria, translation activation by the add riboswitch can be recapitulated in vitro using a pre-transcribed add mRNA, i.e. in the absence of coupling. This is certainly not a general rule, however, as transcriptional pausing plays a key role in RNA folding in bacteria in general. Consistent with this, several examples of regulation based on RNA conformational switches, including the btuB riboswitch mentioned above, require pausing of transcription at specific sites. This pausing presumably prevents the formation of 
unwanted structures and, at least in the case of btuB mRNA, allows coordination of the folding of the riboswitch domain involved in ligand binding with the regulation of gene expression (Perdrizet, Artsimovitch, Furman, Sosnick, \& Pan, 2012).

The property of riboswitches to control gene expression has been exploited to create functional synthetic riboswitches, starting from a single small-molecule-binding RNA aptamer, to activate the translation of heterologous mRNAs. For example, theophylline-responsive riboswitches were synthesized that activate translation initiation of the $x y / R$ gene, encoding the xylose transcriptional repressor, and that of the lacZ gene in the Gram-positive bacterium Bacillus subtilis (Suess, Fink, Berens, Stentz, \& Hillen, 2004) and in the Gram-negative E. coli (Desai \& Gallivan, 2004; Lynch, Desai, Sajja, \& Gallivan, 2007), respectively.

Most of the riboswitches that have been described so far function through a conformational switch between two mutually exclusive states. However, in the case of the add riboswitch, the outcome of a NMR-based study suggests that the regulation mechanism could be governed by three distinct riboswitch conformations, that include two adenine-free conformations instead of only one (Reining et al., 2013).

\subsubsection{A conformational switch between alternative mRNA secondary structures induced by trans- acting factors affects translation initiation.}

As an alternative to sterically hindering the binding of the 30 S ribosomal subunit to the RBS or trapping the subunit in an unproductive complex with the mRNA as discussed above, binding of a regulator outside of the TIR can induce a structural rearrangement of the mRNA, leading to either positive or negative regulation. This can be achieved by RNAs or proteins.

\section{Secondary structure rearrangement induced by trans-acting RNAs.}

The translational control of the rpoS mRNA by multiple sRNAs in E. coli is a nice example of translation activation mediated by alternative base-pairing, in this case involving the regulatory sRNA itself. The RpoS sigma factor is involved in gene expression in stationary phase and in the bacterial response and adaptation to multiple types of stress. Both the synthesis and the stability of the RpoS protein are highly regulated, and at least three sRNAs activate its synthesis by directly pairing to the 5' UTR of rpoS mRNA. Although these three sRNAs, namely DsrA, RprA and ArcZ, have distinct sequences, they pair imperfectly to the same region of the rpoS mRNA, upstream of the TIR. In the unbound conformation, this site forms an imperfect intramolecular helix with the TIR of $r p o S$, thereby limiting translation. As a result, the binding of DsrA, RprA or ArcZ sRNA to the rpoS 5' UTR prevents 
formation of this inhibitory mRNA secondary structure and activates translation initiation (Figure 7A) ((Gottesman, 2019) for a recent review). Other examples of hairpin-competing mechanisms have been reported since then for other sRNAs that activate translation (Prevost et al., 2007; Fröhlich \& Vogel, 2009; Papenfort, Espinosa, Casadesus, \& Vogel, 2015). Furthermore, while a similar mechanism could in theory mediate inhibition by repressor sRNAs (Figure 7B), only very few examples of this kind have been reported so far to our knowledge. This is the case for instance for the SR1 SRNA in Bacillus subtilis whose binding to the coding sequence of the $\operatorname{ahrC}$ mRNA, expressing the transcriptional activator of the $\operatorname{roc} A B C$ and $\operatorname{rocDEF}$ arginine catabolic operons, leads to a decrease in RBS accessibility in vitro (Heidrich, Moll, \& Brantl, 2007). The formation of the SR1-ahrC duplex is facilitated by the CsrA protein, raising the question of the involvement of CsrA in the ahrC structural rearrangement (Müller, Gimpel, Wildenhain, \& Brantl, 2019).

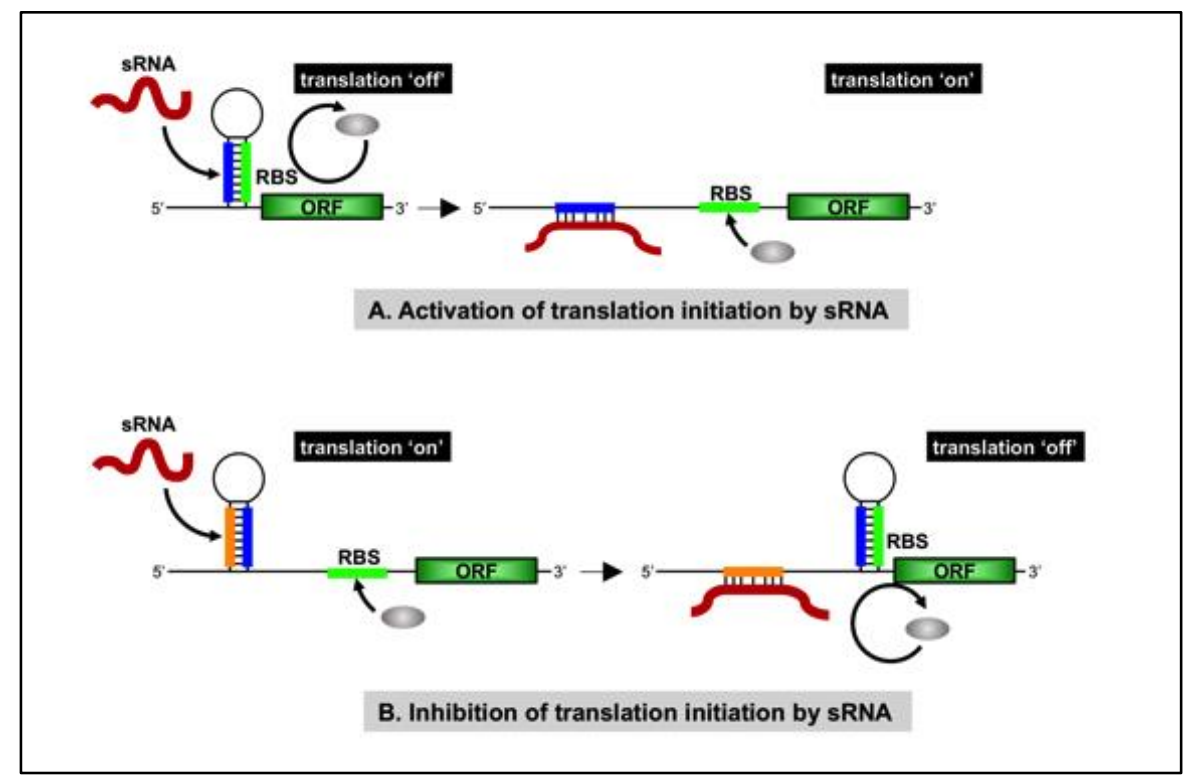

Figure 7. Regulation of translation initiation via rearrangement of mRNA structure by a regulatory small RNA. (A) Pairing of an sRNA (in brown) to an anti-RBS sequence (in blue) unmasks the RBS (in green) and promotes translation initiation of the ORF (translation "on"). (B) Pairing of an sRNA to an antianti-RBS sequence (in orange) can also induce a structural rearrangement leading to RBS occlusion by an anti-RBS sequence and thereby translation inhibition of the ORF (translation "off").

Secondary structure rearrangement induced by trans-acting proteins.

Translation in bacteria can also be influenced, either positively or negatively, by a structural rearrangement of the mRNA that is induced by the binding of an activator or repressor protein (Figure 8). 
Such mechanism is used by the $E$. coli bacteriophage Mu to activate the translation of its mom gene by the phage Com protein. This allows Com to control the DNA-modification function of the Mom protein that provides protection of phage Mu DNA from the host restriction endonucleases. The Com and Mom proteins are encoded by two overlapping genes expressed from the bicistronic com-mom mRNA. The 5' proximal com gene encodes a 62 -amino acid polypeptide that is required for translation of mom. Com binding to the mom TIR results in the destabilization of a stem-loop that is inhibitory for translation, thus rendering the mom SD sequence and GUG translation initiation codon accessible to the incoming ribosome and initiator tRNA (Wulczyn, Bolker, \& Kahmann, 1989; Hattman, Newman, Murthy, \& Nagaraja, 1991; Wulczyn \& Kahmann, 1991). shift induced by a repressor protein. In Pseudomonas æruginosa, the post-transcriptional regulatory protein RsmA directly binds to sequences within the $5^{\prime} U T R$ of the polycistronic $p s / m R N A$, repressing the translation of genes necessary for synthesis of biofilm polysaccharide. It has been proposed that RsmA acts as a repressor by stabilizing a stem-loop structure in the mRNA that blocks ribosome access to the SD sequence of the proximal $p s / A$ gene due to base-pairing with an upstream anti-SD sequence (Irie et al., 2010). This would differ from the most common mechanism of repression by CsrA/RsmA proteins, whose binding to target-mRNAs typically overlaps the TIR and outcompetes the binding of the 30 S ribosomal subunit.

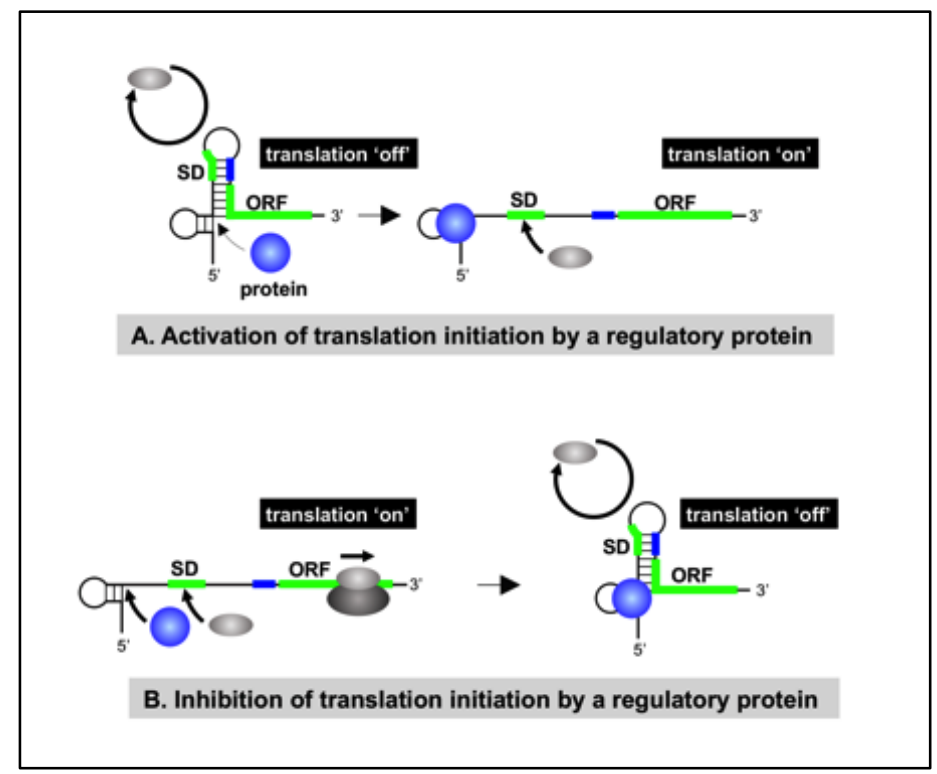

Figure 8. Control of translation initiation via rearrangement of mRNA secondary structure by a regulatory protein. $(A)$ Binding of a regulatory protein to the mRNA induces a structural rearrangement that increases the SD accessibility and thereby activates translation initiation (translation "on"). (B) Binding of a regulatory protein to the mRNA induces a structural rearrangement that decreases the SD accessibility and thereby inhibits translation initiation (translation "off"). 


\section{4. mRNA secondary structures activate translation initiation.}

Investigation of the mode of action of sRNAs that pair to the coding region of the fepA mRNA of $E$. coli, encoding a receptor for iron-siderophore involved in iron uptake, allowed identification of a stemloop structure in the early coding sequence that activates its translation (Jagodnik, Chiaruttini, \& Guillier, 2017). This structure was found to promote the formation of an initiation complex between the mRNA, the 30S ribosomal subunit and the initiator tRNA. Furthermore, this effect is largely independent of the nucleotide sequence of this activating stem-loop (ASL), while the distance between the translation start codon and this stem-loop is important for the activation. Similar structures can be predicted in the early coding region of several mRNAs, and in at least one other case, the predicted ASL was shown to activate gene expression. This second validated ASL is present in the bamA mRNA, encoding one of the essential subunits of the BAM complex responsible for the assembly of $\beta$-barrel proteins in the outer membrane of Gram-negative bacteria. As for the fepA ASL, the bamA ASL promoted formation of a ternary complex between the mRNA, the $30 \mathrm{~S}$ ribosomal subunit and the initiator tRNA, independently of its nucleotide sequence. Importantly, the structure of this ASL is predicted to be conserved in many species that are evolutionarily distinct from $E$. coli, despite a poor conservation at the nucleotide level, suggesting that translation activation mediated by ASLs could be a generally conserved mechanism. Interestingly, introducing structures at similar positions in heterologous genes was previously found to increase gene expression in E. coli (Paulus, Haslbeck, \& Watzele, 2004). Although is is not yet known exactly how these ASLs promote gene expression, it has been hypothesized that they may activate translation initiation by providing a "starting block" for the 30 S ribosomal subunit, which prevents the subunit from "sliding" forward on the mRNA (Figure 9). Considering that the $5^{\prime}$ edge of the ASL is located at position +19 of the ORF, which is exactly contiguous to the $3^{\prime}$ edge of the RBS (Huttenhofer \& Noller, 1994), the ASL would be ideally located to block the subunit at an appropriate position for efficient translation initiation. Interestingly, such an activation by a secondary structure is reminiscent of what has been described in eukaryotic systems where recognition of a non-optimal AUG initiating codon is improved by the presence of a stem-loop structure downstream (Kozak, 1990). However, secondary structures that activate translation are also found upstream of the coding sequence. For example, a stem-loop structure located eight nucleotides upstream of the initiation codon of bacteriophage T4 gene $25 \mathrm{mRNA}$, encoding a structural component of the tail baseplate, has been shown to activate translation initiation. This stem-loop presumably acts by bringing a SD sequence located 27 nucleotides upstream of the initiation codon, which is a very unfavourable spacing for initiation, to a functional spacing of eleven nucleotides (Nivinskas, Malys, Klausa, Vaiskunaite, \& Gineikiene, 1999). The positive involvement of an upstream mRNA structure in translation was also shown in the case of the toxin gene tisB in E. coli. As tisB RBS is poorly accessible, 


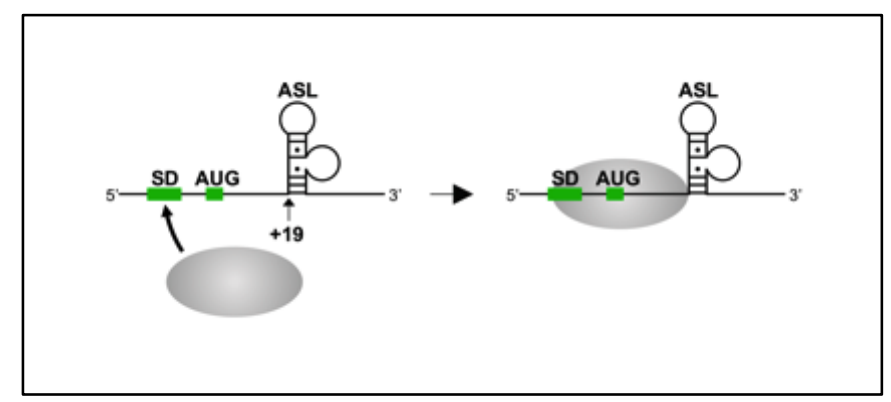

Figure 9. Activation of translation initiation of the $E$. coli fepA mRNA by a secondary structure located in the mRNA coding sequence. The activating stem-loop (ASL) located at position +19 of the coding sequence is shown in a model where it restricts the $30 \mathrm{~S}$ ribosomal subunit (in light gray) to the appropriate position to

initiate translation.

361

its translation depends on the binding of the $30 \mathrm{~S}$ ribosomal subunit to an upstream standby site (Darfeuille, Unoson, Vogel, \& Wagner, 2007) and a 5'-terminal hairpin was unexpectedly found to be required for this process (Romilly, Deindl, \& Wagner, 2019).

\subsection{Contribution of high-throughput approaches}

The findings described above are largely based on single-gene studies, but several large-scale approaches have started to more generally address the relationship between mRNA structure and translation. These results mostly confirmed the previously known correlation between low structure in the TIR and the efficiency of translation initiation step.

Several studies investigating codon usage concluded that a major determinant of the effect of codons at the beginning of ORFs is actually related to the ability of the early coding sequence to form mRNA structures (Kudla, Murray, Tollervey, \& Plotkin, 2009; Goodman, Church, \& Kosuri, 2013; Boël et al., 2016; Bhattacharyya et al., 2018). A poorly structured translation initiation region is also crucial for translation of mRNAs that do not possess a Shine-Dalgarno sequence (Scharff, Childs, Walther, \& Bock, 2011).

Other recent studies used next-generation sequencing (NGS) to relate bacterial structuromes to a concomitant analysis of mRNA levels and translation, by RNAseq and ribosome profiling, respectively. Structuromes were either performed in vitro on total RNA (Del Campo, Bartholomaus, Fedyunin, \& Ignatova, 2015), or in vivo using DMS (Burkhardt et al., 2017; Y. Zhang et al., 2018) or SHAPE reagents (Mustoe et al., 2018). In the latest study, parallel structuromes were determined in vitro and upon inhibiting translation with kasugamycin in vivo to assess the role of translation and other cellular factors in determining mRNA structure. These studies converged on the finding that the region around 
the RBS and the start codon of most mRNAs is poorly structured. In addition, a short structured region 7-12 nts upstream of the start codon was found only in the in vitro study, while the most unstructured region started around nt -20 , which was hypothesized to serve as an unspecific 30 S ribosomal subunit binding-site (Del Campo et al., 2015). This is consistent with the ribosome standby site model proposed by de Smit and Van Duin and the observation that unstructured regions located on the $5^{\prime}$ side of structured RBS promote translation initiation, e.g. in the mRNA for the MS2 coat protein or the E. coli TisB toxin (de Smit \& van Duin, 2003; Darfeuille et al., 2007; Sterk, Romilly, \& Wagner, 2018). At this stage however, from a general point of view, no significant structural difference between the region centered on nt -20 and the -7-12 region was observed in the in vivo structurome studies, and further experiments will be required to assess the validity of this hypothesis for more genes.

\section{2. mRNA SECONDARY STRUCTURES AFFECT TRANSLATION ELONGATION.}

\subsection{The coding sequence of the mRNA not only encodes the primary structure of a protein but} also contains additional information that influences translation elongation rates in bacteria.

After the initiation step, the ribosome proceeds into the elongation step, catalyzing the formation of peptide bonds between amino acids added in an order dictated by the coding sequence of the mRNA. While the control of translation initiation determines how often an mRNA is translated, controlling translation elongation tunes the speed at which it is translated. It has long been recognized that elongation of the polypeptide chain does not proceed at constant speed (Pedersen, 1984; Varenne, Buc, Lloubes, \& Lazdunski, 1984; Sørensen, Kurland, \& Pedersen, 1989; Andersson \& Kurland, 1990). Thus, even though initiation is the step at which bacterial translation is mostly regulated, regulation during the elongation step may also impact gene expression and, in addition to its primary function as a conveyor of the genetic message, the mRNA may contain other genetic instructions that affect the way the message is translated.

A first layer of additional information is provided by the primary structure of the mRNA itself, more precisely by the redundancy of the genetic code. The non-random use of synonymous codons, also called "codon bias", and the availability of the respective isoacceptor tRNAs may have important implications for translation. Codon bias can modulate elongation speed since rare codons, which code for low-abundance tRNAs, delay the progression of the ribosome along the mRNA (Curran \& Yarus, 1989; Berg \& Kurland, 1997; Plotkin \& Kudla, 2011). While it is generally accepted that the codon bias contributes to translation efficiency (and accuracy) by adjusting the elongation rate, how this occurs is still intensively debated (Quax, Claassens, Söll, \& van der Oost, 2015) and references therein). In addition to a role of codon bias in determining translation speed and ribosomal density at key steps, 
thereby ensuring optimal translation (Tuller, Waldman, Kupiec, \& Ruppin, 2010) or protein folding (Komar, 2009; G. Zhang et al., 2009; Spencer, Siller, Anderson, \& Barral, 2012), it has also been reported, as stated above, that limiting RNA structure at the $5^{\prime}$ region of coding sequences rather than codon rarity alone contributed to the effect of codon usage on translation (Kudla et al., 2009; Goodman et al., 2013; Boël et al., 2016; Bhattacharyya et al., 2018).

\subsection{Translational pausing "noise" caused by the intrinsic propensity of RNA to fold into secondary structure.}

Besides codon usage, a second layer of information that shapes translation in bacteria is provided by the secondary structure adopted by the mRNA. As stated for translation initiation, secondary structures located at the RBS and the very beginning of the coding sequence are important modulators of translation efficiency. This may be true for elongation as well, because translating ribosomes face the potential thermodynamic and kinetic barriers of RNA secondary structure motifs or even highly structured domains like pseudoknots (Takyar, Hickerson, \& Noller, 2005; Qu et al., 2011). It has been shown that mRNA secondary structures indeed influence the translation elongation rate in vitro. This influence was nicely illustrated by elegant optical-tweezer experiments showing that the secondary structure of mRNA determines ribosome pausing, and thus the overall rate of translation, and, importantly, that destabilization of hairpins decreases the duration of pauses without affecting translocation time (Wen et al., 2008). Similarly, an in vitro study using single molecule fluorescence resonance energy transfer (FRET) to measure reaction rates for specific steps during elongation highlighted the role played by stem-loops and pseudoknots in slowing down or even halting the movement of the ribosome on mRNA (Chen et al., 2013). The movement of the translating ribosome along the mRNA during elongation necessarily disrupts these structures. Consistently, it has been shown that pausing or braking of ribosomes at RNA helices is very transient due to their remarkable ability to unwind downstream helices of very high stability (Takyar et al., 2005).

In addition to the helicase activity of the ribosome, the coupling of transcription and translation in bacteria ((Proshkin, Rahmouni, Mironov, \& Nudler, 2010) and references therein) suggests that the first ribosome has the benefit of an unstructured mRNA for translation. However, as the time needed to form a simple hairpin helix is much faster than ribosome association to the mRNA, i.e. an RNA helix folds in the millisecond range (Crothers et al., 1974; Pörschke, 1974) while initiation frequency is in the second range (Kennell \& Riezman, 1977), hairpins should have enough time to refold between the subsequent (uncoupled) translating ribosomes. Thus, although extent of mRNA secondary structure measured in vitro certainly overestimates the degree to which they occur in vivo, cellular mRNAs are structured to some degree. In line with this, transcriptome-wide chemical probing approaches have 
shown that a lower fraction of $E$. coli mRNA secondary structures persists in vivo compared to that detected in vitro or upon inhibition of translation (Burkhardt et al., 2017; Mustoe et al., 2018). This highlights the importance of energy-dependent processes at work during elongation, e.g the unwinding of mRNA helices by ATP-dependent helicases or translating ribosomes, or passive events, such as the association of RNA binding proteins, in shaping mRNAs in the cell. In addition, it has been proposed that the intrinsic propensity of RNA to rapidly form secondary structures within coding sequences is cancelled out by selection of codons for high-abundant tRNAs that are translated faster and in general re-equilibrate the overall translation speed (Gorochowski, Ignatova, Bovenberg, \& Roubos, 2015). Nevertheless, persistant secondary structures that cause ribosomes to slow or stall on mRNA have probably been selected for functional reasons that are yet unknown in most cases and deserve further investigation to define their roles in bacteria. So far, only a small sub-set of these structures have been characterized whose role is to transiently stall ribosomes translating $E$. coli mRNAs encoding membrane proteins, most likely to regulate integration of these proteins into the membrane (Del Campo et al., 2015).

Interestingly, ribosome profiling data point to strong variations in the translation efficiency among the different genes of a polycistronic mRNA, allowing for instance to reach the stoichiometry of the different components of multi-protein complexes (Li, Burkhardt, Gross, \& Weissman, 2014). While more experiments are needed to understand the underlying molecular mechanism in most cases, it is likely that mRNA secondary structures could be involved in this process and could act at the translation initiation and/or elongation steps to fine-tune protein synthesis.

A combination of ribosome profiling and in vivo structuromes also revealed different possible roles for mRNA secondary structures in regions outside of the RBS. Using DMS-based approaches, it has been proposed that mRNAs present a similar degree of structure within a given ORF and that this ORFwide structure is an important determinant of translation (Burkhardt et al., 2017; Y. Zhang et al., 2018). In contrast, SHAPE-based data did not identify a significant correlation between the structure of the coding sequences and their translation, except for the TIR region (Mustoe et al., 2018). This study instead revealed structures within ORFs that could play an important role in translation, by mediating translational coupling or serving as regulatory elements. Several differences in the experimental process could explain these different conclusions, among which are the probing method and the overall sample preparation procedure, the criteria used for the bioinformatics approaches, as well as the set of mRNAs considered in the final analysis. More generally, the use of high-throughput approaches to determine RNA structure may not be optimal for poorly abundant RNAs. In addition, because structurome analysis questions the structure of the whole population of RNA, it will provide 
in most cases an average of the structures that can be adopted by a given region of an RNA molecule. In other words, alternative foldings as well as different structures that could correspond to different RNA isoforms may not necessarily be discriminated in these approaches. The co-transcriptional folding of RNA will also not be addressed by the most classical structurome analyses. However, despite these current limitations, there is no doubt that the generalization of these powerful approaches in the years to come will provide significant advances of our understanding of translation regulation on a global scale in diverse organisms.

\subsection{Stem-loop structures govern the recoding of the mRNA.}

In general, the role of mRNA secondary structures in translation elongation is still much less understood than its role in translation initiation. In some mRNAs, an additional layer of information is embedded in the mRNA coding sequence that specifies a change in how the genetic code is read out by the ribosome. In some cases, this information alters the reading frame, while in other cases, the codon usage is altered. This phenomenon, called "recoding", is determined by specific instructions, called "recoding signals", embedded in the mRNA (Gesteland, Weiss, \& Atkins, 1992).

\subsubsection{Recoding by frameshifting of the coding sequence.}

Some mRNAs carry special sequence information and structural elements in their mRNAs that enable ribosomes to slip either backward or forward, hence shifting the reading frame. This event, termed "Programmed ribosomal frameshifting" (PRF), goes well beyond bacteria, since organisms from all three kingdoms and viruses use frameshifting to regulate gene expression (Atkins, Loughran, Bhatt, Firth, \& Baranov, 2016). In the case of a -1 frameshift, ribosomes slip in the $5^{\prime}$ direction on mRNAs by one nucleotide, whereas +1 frameshifting results in forward, or 3 ', slippage by one nucleotide. In rare cases the ribosome can also shift by $-2,-4,+2,+5$, or even +6 nucleotides (Weiss, Dunn, Atkins, \& Gesteland, 1987; Lainé, Thouard, Komar, \& Rossignol, 2008; Fang et al., 2012; Yan, Wen, Bustamante, \& Tinoco, 2015). A classical example of bacterial programmed frameshifting is provided by the translation of the $d n a X$ gene of $E$. coli (Figure 10A) encoding two subunits of DNA polymerase III, namely proteins $\tau$ and $\gamma$ (Blinkowa \& Walker, 1990; Flower \& McHenry, 1990; Tsuchihashi \& Kornberg, 1990). Protein $\gamma$ is shorter than $\tau$ due to a programmed -1 frameshift provoked by the tandem slippage of the peptidyl-tRNA and the aminoacyl-tRNA occupying the adjacent $P$ and $A$ ribosomal sites, respectively. As a result, the new frame terminates at a UGA stop codon located two bp downstream of the 'slippery' sequence. The frameshift event is very efficient, since it reprograms fifty per cent of the ribosomes, thus ensuring that both proteins are produced in a 1:1 ratio. The frameshift signals are a stimulatory SD-like sequence located few nucleotides upstream of the slippery site, a heptanucleotide slippery sequence at which ribosomes shift to the -1 frame and 

accepted that the stem-loop provokes ribosome pausing on the slippery sequence decreasing the rate of ribosomal translocation (Kim et al., 2014). However, the intimate mechanism by which the downstream stimulatory stem-loop promotes efficient frameshifting has not emerged yet.

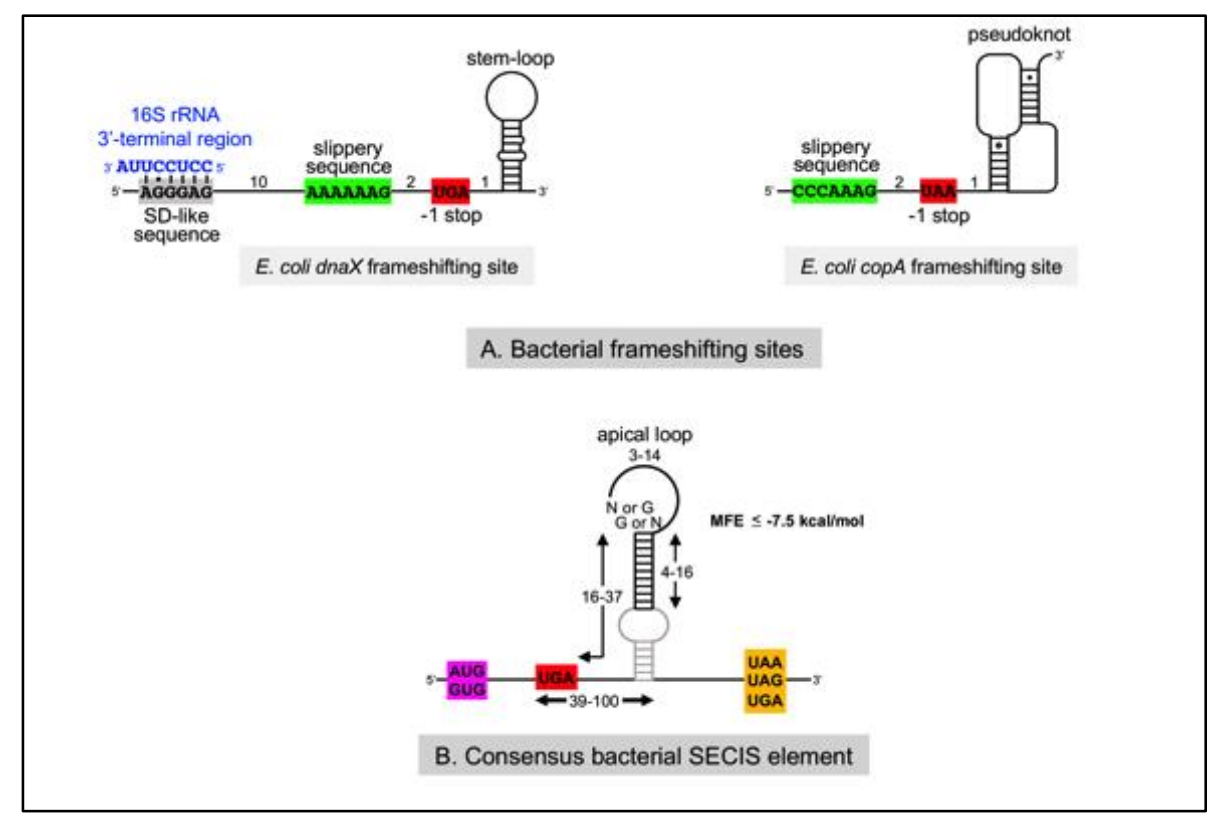

Figure 10. Modulation of mRNA recoding by specific secondary structures. $(A)$ Models of the slippery sites of E. coli dnaX and copA genes, based on (Larsen, Wills, Gesteland, \& Atkins, 1994; Meydan et al., 2017), respectively. Frameshift sites and downstream stop codons in the -1 frame are boxed in green and red, respectively. The upstream SD-like sequence present on $d n a X$ mRNA is boxed in gray and is shown in base pairing interaction with the 3'-terminus of $16 \mathrm{~S}$ rRNA (in blue). The numbers indicate the number of nucleotides separating the indicated sites. (B) Consensus bacterial SECIS element based on (Y. Zhang \& Gladyshev, 2005). The start codon (AUG or GUG) of the gene subjected to recoding is boxed in purple while the recoded UGA stop codon and the UAA, UAG and UGA stop codons specifying arrest of translation following recoding are boxed in red and orange, respectively. The numbers are as in $(A)$.

More recently, it has been shown that expression of the copA gene in E. coli, encoding both the 834-amino acids copper transporter CopA and the 70-amino acid copper chaperone $\operatorname{CopA}(\mathrm{Z})$, undergoes recoding by PRF. Translation of $\operatorname{CopA}(Z)$ results from highly efficient -1 frameshift at a slippery sequence, which is stimulated by the presence of a downstream pseudoknotted stem-loop (Meydan et al., 2017). The -1 frame terminates at a UAA stop codon located two bp downstream of the slippery sequence. It should be noted that ribosome profiling data points to an abrupt drop in ribosome density immediately after the $70^{\text {th }}$ codon, supporting the view that a large fraction of ribosomes shift to the -1 frame and terminate translation of copA after the $70^{\text {th }}$ codon. The conservation of the co-occurrence of a slippery sequence together with a downstream pseudoknot at the appropriate distance in a range of bacterial species strongly suggests that co-expression of the 
transporter and its chaperone is a beneficial trait allowing the proper regulation of copper homeostasis.

\subsubsection{Recoding the coding sequence by altering codon usage}

In E. coli, the coding sequences of a few genes coding for selenoproteins, mostly oxido-reductases, end with an opal UGA codon that co-translationally directs the incorporation of selenocysteine instead of acting as a translation termination codon (Zinoni, Birkmann, Leinfelder, \& Böck, 1987). This UGA recoding process requires a cis-acting mRNA element called SECIS (selenocysteine insertion sequence), consisting of 40-nucleotide sequence on average that form a stem-loop structure (Zinoni, Heider, \& Böck, 1990). The sequence forming the SECIS element is located immediately downstream of the recoded UGA codon. A number of tran-acting elements are also required for selenocysteine incorporation, including the specific minor tRNA ${ }^{\mathrm{Sec}}$, which is a specialized tRNA containing a UCA anticodon (Leinfelder, Zehelein, Mandrand-Berthelot, \& Böck, 1988) and a special elongation factor protein, called SelB, which replaces the function of elongation factor EF-Tu (Forchhammer, Leinfelder, \& Böck, 1989). SelB exhibits extensive sequence homology to EF-Tu and has been shown to bind specifically to both Sec-tRNA ${ }^{\text {Sec }}$ and the SECIS element in vitro (Fourmy, Guittet, \& Yoshizawa, 2002). The bacterial SECIS stem-loop element is defined by characteristic nucleotide sequences and secondary structure base-pairing patterns. The essential region for selenocysteine insertion is located in its apical loop, which includes the binding site for SelB. Once bound to the SECIS element, SelB in turn recruits Sec-tRNA ${ }^{\text {Sec }}$ to the ribosomal A-site and mediates elongation at the in-frame UGA by competing with release factor RF2 (Mansell, Guévremont, Poole, \& Tate, 2001). Therefore, the SECIS element acts as a binding site for SelB rather than a roadblock to slow the movement of the ribosome along the mRNA.

\section{A ROLE FOR MRNA SECONDARY STRUCTURES IN TRANSLATION TERMINATION?}

Compared to their role in regulating translation initiation and elongation, our current knowledge of the function performed by mRNA secondary structure motifs in translation termination lags by far behind. Recently, a global E. coli mRNA structure analysis performed in vitro, coupled to deepsequencing and ribosome profiling detected an enrichment of ribosome density upstream of a persistent mRNA secondary structure located 4-8 nucleotides upstream of the ochre UAA termination codon (Del Campo et al., 2015). It was suggested that this secondary structure slows the translating ribosome to assist the appropriate positioning of the ribosomal A-site for accurate decoding of the UAA codon. However, SHAPE analysis of the $E$. coli structurome in vivo did not identify such a structure (Mustoe et al., 2018), and its existence and precise role thus remain to be investigated. 
Conclusion

Multiple studies, conducted either at the single-gene level or on a genome-wide scale, indicate that

562 increased bacterial translation efficiency correlates mostly with a reduced propensity of mRNA to form secondary structures, especially in the TIR. Specific mRNA secondary structures allow the regulation of translational events like ribosome binding, translational coupling and recoding, as well as mRNA decay. However, an understanding of the effects of mRNA secondary structures on termination and ribosome recycling, collisions between translating ribosomes in polysomes, coupling between transcription and translation in bacteria or co-translational protein folding and quality control lags well behind. Similar to the incorporation of selenocysteine via SelB, whether ribosomal or non-ribosomal factors can promote translation of mRNAs displaying different structural content, e.g. by recruiting or targeting ribosomes to specific mRNAs, is also an important and still poorly addressed question. Finally, research has mostly focused on the impact of secondary RNA structures so far, and the role of tertiary RNA structures such as triple helices, loop-loop interactions, or pseudoknots just to name a few, will have to be determined as well in the future.

The ascent of genome-wide approaches based on NGS technologies applied to ribosome profiling and structure analyses has allowed scientists to address new questions regarding the relationship between mRNA structure and translation. While some of the first results may initially appear contradictory, more ribosome profiling and structurome data, from different growth conditions and the use of more standardized steps in sample preparation and data analysis between different laboratories, will be key not only to understanding the current differences, but more generally to address the future questions in the field. The combination of these genome-wide approaches has certainly proved to be a very powerful tool to begin to unravel and map structural features in mRNA that are involved in translational regulation or recoding; nevertheless, the intimate details of the molecular mechanisms governing these events can only be dissected following investigation conducted on a single gene-scale.

The CNRS and the "Initiative d'Excellence" program from the French State (Grant "DYNAMO", ANR11-LABX-0011) supported the writing of this review. 
We thank the members of the group for discussions and support, and are grateful to Ciaran Condon for comments on the manuscript.

\section{References}

Andersson, S. G., \& Kurland, C. G. (1990). Codon preferences in free-living microorganisms. Microbiological Reviews, 54(2), 198-210.

Atkins, J. F., Loughran, G., Bhatt, P. R., Firth, A. E., \& Baranov, P. V. (2016). Ribosomal frameshifting and transcriptional slippage: From genetic steganography and cryptography to adventitious use. Nucleic Acids Research, 44(15), 7007-7078. https://doi.org/10.1093/nar/gkw530

Babitzke, P., Lai, Y.-J., Renda, A., \& Romeo, T. (2019). Posttranscription Initiation Control of Gene Expression Mediated by Bacterial RNA-Binding Proteins. Annual Review of Microbiology, 73(1), annurev-micro-020518-115907. https://doi.org/10.1146/annurev-micro-020518-115907

Batey, R. T., Rambo, R. P., \& Doudna, J. A. (1999). Tertiary Motifs in RNA Structure and Folding. Angewandte Chemie (International Ed. in English), 38(16), 2326-2343.

Beisel, C. L., Updegrove, T. B., Janson, B. J., \& Storz, G. (2012). Multiple factors dictate target selection by Hfq-binding small RNAs. The EMBO Journal, 31(8), 1961-1974. https://doi.org/10.1038/emboj.2012.52

Belasco, J. G. (2010). All things must pass: Contrasts and commonalities in eukaryotic and bacterial mRNA decay. Nature Reviews. Molecular Cell Biology, 11(7), 467-478. https://doi.org/10.1038/nrm2917

Berg, O. G., \& Kurland, C. G. (1997). Growth rate-optimised tRNA abundance and codon usage. Journal of Molecular Biology, 270(4), 544-550. https://doi.org/10.1006/jmbi.1997.1142

Bhattacharyya, S., Jacobs, W. M., Adkar, B. V., Yan, J., Zhang, W., \& Shakhnovich, E. I. (2018). Accessibility of the Shine-Dalgarno Sequence Dictates N-Terminal Codon Bias in E. coli. Molecular Cell, 70(5), 894-905.e5. https://doi.org/10.1016/j.molcel.2018.05.008

Blinkowa, A. L., \& Walker, J. R. (1990). Programmed ribosomal frameshifting generates the Escherichia coli DNA polymerase III gamma subunit from within the tau subunit reading frame. Nucleic Acids Research, 18(7), 1725-1729. https://doi.org/10.1093/nar/18.7.1725

Boël, G., Letso, R., Neely, H., Price, W. N., Wong, K.-H., Su, M., ... Hunt, J. F. (2016). Codon influence on protein expression in E. coli correlates with mRNA levels. Nature, 529(7586), 358-363. https://doi.org/10.1038/nature16509

Briani, F., Carzaniga, T., \& Dehò, G. (2016). Regulation and functions of bacterial PNPase. Wiley Interdisciplinary Reviews: RNA, 7(2), 241-258. https://doi.org/10.1002/wrna.1328

Brion, P., \& Westhof, E. (1997). Hierarchy and dynamics of RNA folding. Annual Review of Biophysics and Biomolecular Structure, 26, 113-137. https://doi.org/10.1146/annurev.biophys.26.1.113

Burkhardt, D. H., Rouskin, S., Zhang, Y., Li, G.-W., Weissman, J. S., \& Gross, C. A. (2017). Operon mRNAs are organized into ORF-centric structures that predict translation efficiency. ELife, 6, e22037. 
Busch, A., Richter, A. S., \& Backofen, R. (2008). IntaRNA: Efficient prediction of bacterial sRNA targets incorporating target site accessibility and seed regions. Bioinformatics (Oxford, England), 24(24), 2849-2856. https://doi.org/10.1093/bioinformatics/btn544

Cerretti, D. P., Mattheakis, L. C., Kearney, K. R., Vu, L., \& Nomura, M. (1988). Translational 633 regulation of the spc operon in Escherichia coli. Identification and structural analysis of the target site for S8 repressor protein. J. Mol. Biol., 204(2), 309-329.

Chen, C., Zhang, H., Broitman, S. L., Reiche, M., Farrell, I., Cooperman, B. S., \& Goldman, Y. E. (2013). Dynamics of translation by single ribosomes through mRNA secondary structures. Nature Structural \& Molecular Biology, 20(5), 582-588. https://doi.org/10.1038/nsmb.2544

Chiaruttini, C., Milet, M., \& Springer, M. (1996). A long-range RNA-RNA interaction forms a pseudoknot required for translational control of the IF3-L35-L20 ribosomal protein operon in Escherichia coli. EMBO J., 15, 4402-4413.

Chiaruttini, C., Milet, M., \& Springer, M. (1997). Translational coupling by modulation of feedback repression in the IF3 operon of Escherichia coli. Proc. Natl. Acad. Sci. USA, 94, 9208-9213.

Curran, J. F., \& Yarus, M. (1989). Rates of aminoacyl-tRNA selection at 29 sense codons in vivo. Journal of Molecular Biology, 209(1), 65-77. https://doi.org/10.1016/0022-2836(89)90170-8

647 Darfeuille, F., Unoson, C., Vogel, J., \& Wagner, E. G. (2007). An antisense RNA inhibits translation 648 by competing with standby ribosomes. Mol Cell, 26(3), 381-392. 649 https://doi.org/10.1016/j.molcel.2007.04.003 de Smit, M. H., \& van Duin, J. (2003). Translational standby sites: How ribosomes may deal with the rapid folding kinetics of mRNA. J Mol Biol, 331(4), 737-743.

Del Campo, C., Bartholomaus, A., Fedyunin, I., \& Ignatova, Z. (2015). Secondary Structure across the Bacterial Transcriptome Reveals Versatile Roles in mRNA Regulation and Function. PLoS Genet, 11(10), e1005613. https://doi.org/10.1371/journal.pgen.1005613

Desai, S. K., \& Gallivan, J. P. (2004). Genetic screens and selections for small molecules based on a synthetic riboswitch that activates protein translation. Journal of the American Chemical Society, 126(41), 13247-13254. https://doi.org/10.1021/ja048634j

Dubnau, D. (1985). Induction of ermC requires translation of the leader peptide. The EMBO Journal, 4(2), 533-537.

660 Duval, M., Korepanov, A., Fuchsbauer, O., Fechter, P., Haller, A., Fabbretti, A., ... Marzi, S. (2013). 661 Escherichia coli ribosomal protein S1 unfolds structured mRNAs onto the ribosome for active translation initiation. PLoS Biol, 11(12), e1001731. https://doi.org/10.1371/journal.pbio.1001731 
Flower, A. M., \& McHenry, C. S. (1990). The gamma subunit of DNA polymerase III holoenzyme of 668 Escherichia coli is produced by ribosomal frameshifting. Proceedings of the National Academy of Sciences of the United States of America, 87(10), 3713-3717. https://doi.org/10.1073/pnas.87.10.3713

Forchhammer, K., Leinfelder, W., \& Böck, A. (1989). Identification of a novel translation factor necessary for the incorporation of selenocysteine into protein. Nature, 342(6248), 453-456. https://doi.org/10.1038/342453a0

673 Fourmy, D., Guittet, E., \& Yoshizawa, S. (2002). Structure of prokaryotic SECIS mRNA hairpin and 674 its interaction with elongation factor SelB. Journal of Molecular Biology, 324(1), 137-150. 675 https://doi.org/10.1016/s0022-2836(02)01030-6

Fröhlich, K. S., \& Vogel, J. (2009). Activation of gene expression by small RNA. Current Opinion in Microbiology, 12(6), 674-682. https://doi.org/10.1016/j.mib.2009.09.009

Goodman, D. B., Church, G. M., \& Kosuri, S. (2013). Causes and effects of N-terminal codon bias in

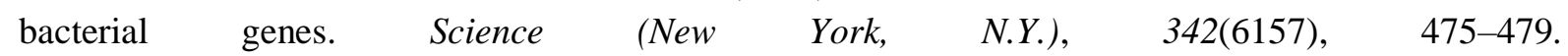
https://doi.org/10.1126/science.1241934

Gorochowski, T. E., Ignatova, Z., Bovenberg, R. A. L., \& Roubos, J. A. (2015). Trade-offs between tRNA abundance and mRNA secondary structure support smoothing of translation elongation rate. Nucleic Acids Research, 43(6), 3022-3032. https://doi.org/10.1093/nar/gkv199

Gottesman, S. (2019). Trouble is coming: Signaling pathways that regulate general stress responses in https://doi.org/10.1074/jbc.REV119.005593

Gregory, R. J., Cahill, P. B., Thurlow, D. L., \& Zimmermann, R. A. (1988). Interaction of Escherichia coli ribosomal protein S8 with its binding sites in ribosomal RNA and messenger RNA. J. Mol. Biol., 204(2), 295-307.

Gualerzi, C. O., \& Pon, C. L. (2015). Initiation of mRNA translation in bacteria: Structural and dynamic

aspects. Cellular and Molecular Life Sciences: CMLS, 72(22), 4341-4367. https://doi.org/10.1007/s00018-015-2010-3

Guillier, M., Allemand, F., Raibaud, S., Dardel, F., Springer, M., \& Chiaruttini, C. (2002). Translational feedback regulation of the gene for L35 in Escherichia coli requires binding of ribosomal protein L20 to two sites in its leader mRNA: a possible case of ribosomal RNA-messenger RNA molecular mimicry. RNA, 8(7), 878-889.

Gupta, P., Kannan, K., Mankin, A. S., \& Vázquez-Laslop, N. (2013). Regulation of gene expression by macrolide-induced ribosomal frameshifting. Molecular Cell, 52(5), 629-642. 
Heidrich, N., Moll, I., \& Brantl, S. (2007). In vitro analysis of the interaction between the small RNA SR1 and its primary target ahrC mRNA. Nucleic Acids Res., 35(13), 4331-4346. https://doi.org/10.1093/nar/gkm439

Holmqvist, E., Wright, P. R., Li, L., Bischler, T., Barquist, L., Reinhardt, R., ... Vogel, J. (2016). Global RNA recognition patterns of post-transcriptional regulators Hfq and CsrA revealed by UV crosslinking in vivo. EMBO J, 35(9), 991-1011. https://doi.org/10.15252/embj.201593360

Horinouchi, S., \& Weisblum, B. (1980). Posttranscriptional modification of mRNA conformation: Mechanism that regulates erythromycin-induced resistance. Proceedings of the National Academy of Sciences of the United States of America, 77(12), 7079-7083. https://doi.org/10.1073/pnas.77.12.7079

Huttenhofer, A., \& Noller, H. F. (1994). Footprinting mRNA-ribosome complexes with chemical probes. EMBO J, 13(16), 3892-3901.

Irie, Y., Starkey, M., Edwards, A. N., Wozniak, D. J., Romeo, T., \& Parsek, M. R. (2010). Pseudomonas aeruginosa biofilm matrix polysaccharide Psl is regulated transcriptionally by RpoS and posttranscriptionally by RsmA. Molecular Microbiology, 78(1), 158-172. https://doi.org/10.1111/j.13652958.2010.07320.x

Jagodnik, J., Chiaruttini, C., \& Guillier, M. (2017). Stem-Loop Structures within mRNA Coding Sequences Activate Translation Initiation and Mediate Control by Small Regulatory RNAs. Mol Cell, 68(1), 158-170 e3. https://doi.org/10.1016/j.molcel.2017.08.015

Johansson, J., Mandin, P., Renzoni, A., Chiaruttini, C., Springer, M., \& Cossart, P. (2002). An RNA thermosensor controls expression of virulence genes in Listeria monocytogenes. Cell, 110(5), 551-561. https://doi.org/10.1016/s0092-8674(02)00905-4

Kennell, D., \& Riezman, H. (1977). Transcription and translation initiation frequencies of the Escherichia coli lac operon. J Mol Biol, 114(1), 1-21.

Kim, H.-K., Liu, F., Fei, J., Bustamante, C., Gonzalez, R. L., \& Tinoco, I. (2014). A frameshifting stimulatory stem loop destabilizes the hybrid state and impedes ribosomal translocation. Proceedings of the National Academy of Sciences, 111(15), 5538-5543. https://doi.org/10.1073/pnas.1403457111

Kolb, F. A., Engdahl, H. M., Slagter-Jager, J. G., Ehresmann, B., Ehresmann, C., Westhof, E., ... Romby, P. (2000). Progression of a loop-loop complex to a four-way junction is crucial for the activity of a regulatory antisense RNA. EMBO J., 19(21), 5905-5915.

Komar, A. A. (2009). A pause for thought along the co-translational folding pathway. Trends in Biochemical Sciences, 34(1), 16-24. https://doi.org/10.1016/j.tibs.2008.10.002

Kortmann, J., \& Narberhaus, F. (2012). Bacterial RNA thermometers: Molecular zippers and switches. Nature Reviews. Microbiology, 10(4), 255-265. https://doi.org/10.1038/nrmicro2730

Kozak, M. (1990). Downstream secondary structure facilitates recognition of initiator codons by eukaryotic ribosomes. Proceedings of the National Academy of Sciences, 87(21), 8301-8305. https://doi.org/10.1073/pnas.87.21.8301

Kudla, G., Murray, A. W., Tollervey, D., \& Plotkin, J. B. (2009). Coding-sequence determinants of 
gene expression in Escherichia coli. Science (New York, N.Y.), 324(5924), 255-258. https://doi.org/10.1126/science.1170160

Lainé, S., Thouard, A., Komar, A. A., \& Rossignol, J.-M. (2008). Ribosome can resume the translation in both +1 or -1 frames after encountering an AGA cluster in Escherichia coli. Gene, 412(1-2), 95-101. https://doi.org/10.1016/j.gene.2008.01.018

Landick, R., Carey, J., \& Yanofsky, C. (1987). Detection of transcription-pausing in vivo in the trp operon leader region. Proceedings of the National Academy of Sciences of the United States of America, 84(6), 1507-1511. https://doi.org/10.1073/pnas.84.6.1507

Larsen, B., Wills, N. M., Gesteland, R. F., \& Atkins, J. F. (1994). RRNA-mRNA base pairing stimulates a programmed -1 ribosomal frameshift. Journal of Bacteriology, 176(22), 6842-6851. https://doi.org/10.1128/jb.176.22.6842-6851.1994

Leinfelder, W., Zehelein, E., Mandrand-Berthelot, M. A., \& Böck, A. (1988). Gene for a novel tRNA species that accepts L-serine and cotranslationally inserts selenocysteine. Nature, 331(6158), 723-725. https://doi.org/10.1038/331723a0

Lemay, J.-F., Desnoyers, G., Blouin, S., Heppell, B., Bastet, L., St-Pierre, P., ... Lafontaine, D. A. (2011). Comparative study between transcriptionally- and translationally-acting adenine riboswitches reveals key differences in riboswitch regulatory mechanisms. PLoS Genetics, 7(1), e1001278. https://doi.org/10.1371/journal.pgen.1001278

Lesage, P., Chiaruttini, C., Dondon, J., Graffe, M., Milet, M., \& Springer, M. (1992). Messenger RNA secondary structure and translational coupling in the E.coli operon encoding translation initiation factor IF3 and the ribosomal proteins, L35 and L20. J. Mol. Biol., 228, 366-386.

Lesage, P., Truong, H. N., Graffe, M., Dondon, J., \& Springer, M. (1990). Translated translational operator in Escherichia coli : Autoregulation in the infC-rpmI-rplT operon. J. Mol. Biol., 213, 465-475.

Li, G.-W., Burkhardt, D., Gross, C., \& Weissman, J. S. (2014). Quantifying Absolute Protein Synthesis Rates Reveals Principles Underlying Allocation of Cellular Resources. Cell, 157(3), 624-635. https://doi.org/10.1016/j.cell.2014.02.033

Loh, E., Righetti, F., Eichner, H., Twittenhoff, C., \& Narberhaus, F. (2018). RNA Thermometers in Bacterial Pathogens. Microbiology Spectrum, 6(2). https://doi.org/10.1128/microbiolspec.RWR-00122017

Lovett, P. S. (1996). Translation attenuation regulation of chloramphenicol resistance in bacteria-A review. Gene, 179(1), 157-162. https://doi.org/10.1016/s0378-1119(96)00420-9

Lynch, S. A., Desai, S. K., Sajja, H. K., \& Gallivan, J. P. (2007). A high-throughput screen for synthetic riboswitches reveals mechanistic insights into their function. Chemistry \& Biology, 14(2), 173-184. https://doi.org/10.1016/j.chembiol.2006.12.008

Mangeol, P., Bizebard, T., Chiaruttini, C., Dreyfus, M., Springer, M., \& Bockelmann, U. (2011). Probing ribosomal protein-RNA interactions with an external force. Proc Natl Acad Sci U S A, 108(45), 18272-18276. https://doi.org/10.1073/pnas.1107121108

Mann, M., Wright, P. R., \& Backofen, R. (2017). IntaRNA 2.0: Enhanced and customizable prediction of RNA-RNA interactions. Nucleic Acids Research, 45(W1), W435-W439. 
Mansell, J. B., Guévremont, D., Poole, E. S., \& Tate, W. P. (2001). A dynamic competition between release factor 2 and the tRNA(Sec) decoding UGA at the recoding site of Escherichia coli formate dehydrogenase H. The EMBO Journal, 20(24), 7284-7293. https://doi.org/10.1093/emboj/20.24.7284

Masachis, S., \& Darfeuille, F. (2018). Type I Toxin-Antitoxin Systems: Regulating Toxin Expression via Shine-Dalgarno Sequence Sequestration and Small RNA Binding. Microbiology Spectrum, 6(4). https://doi.org/10.1128/microbiolspec.RWR-0030-2018

Masachis, S., Tourasse, N. J., Lays, C., Faucher, M., Chabas, S., Iost, I., \& Darfeuille, F. (2019). A genetic selection reveals functional metastable structures embedded in a toxin-encoding mRNA. ELife, 8. https://doi.org/10.7554/eLife.47549

Mearls, E. B., Jackter, J., Colquhoun, J. M., Farmer, V., Matthews, A. J., Murphy, L. S., ... Camp, A. H. (2018). Transcription and translation of the sigG gene is tuned for proper execution of the switch from early to late gene expression in the developing Bacillus subtilis spore. PLOS Genetics, 14(4), e1007350. https://doi.org/10.1371/journal.pgen.1007350

Merianos, H. J., Wang, J., \& Moore, P. B. (2004). The structure of a ribosomal protein S8/spc operon mRNA complex. RNA (New York, N.Y.), 10(6), 954-964. https://doi.org/10.1261/rna.7030704

Meydan, S., Klepacki, D., Karthikeyan, S., Margus, T., Thomas, P., Jones, J. E., ... Mankin, A. S. (2017). Programmed Ribosomal Frameshifting Generates a Copper Transporter and a Copper Chaperone from the Same Gene. Molecular Cell, 65(2), 207-219. https://doi.org/10.1016/j.molcel.2016.12.008

Miladi, M., Montaseri, S., Backofen, R., \& Raden, M. (2018). Integration of accessibility data from structure probing into RNA-RNA interaction prediction. Bioinformatics (Oxford, England). https://doi.org/10.1093/bioinformatics/bty1029

Morita, M. T., Tanaka, Y., Kodama, T. S., Kyogoku, Y., Yanagi, H., \& Yura, T. (1999). Translational induction of heat shock transcription factor sigma32: Evidence for a built-in RNA thermosensor. Genes Dev., 13(6), 655-665.

Müller, P., Gimpel, M., Wildenhain, T., \& Brantl, S. (2019). A new role for CsrA: Promotion of complex formation between an sRNA and its mRNA target in Bacillus subtilis. RNA Biology, 16(7), 972-987. https://doi.org/10.1080/15476286.2019.1605811

Murakami, A., Nakatogawa, H., \& Ito, K. (2004). Translation arrest of SecM is essential for the basal and regulated expression of SecA. Proceedings of the National Academy of Sciences of the United States of America, 101(33), 12330-12335. https://doi.org/10.1073/pnas.0404907101

Mustoe, A. M., Busan, S., Rice, G. M., Hajdin, C. E., Peterson, B. K., Ruda, V. M., ... Weeks, K. M. (2018). Pervasive Regulatory Functions of mRNA Structure Revealed by High-Resolution SHAPE Probing. Cell, 173(1), 181-195.e18. https://doi.org/10.1016/j.cell.2018.02.034

Nahvi, A., Sudarsan, N., Ebert, M. S., Zou, X., Brown, K. L., \& Breaker, R. R. (2002). Genetic control by a metabolite binding mRNA. Chem. Biol., 9(9), 1043.

Nakatogawa, H., Murakami, A., \& Ito, K. (2004). Control of SecA and SecM translation by protein secretion. Current Opinion in Microbiology, 7(2), 145-150. https://doi.org/10.1016/j.mib.2004.01.001 

Interdisciplinary Reviews: RNA, 5(1), 31-48. https://doi.org/10.1002/wrna.1195

Nivinskas, R., Malys, N., Klausa, V., Vaiskunaite, R., \& Gineikiene, E. (1999). Post-transcriptional control of bacteriophage T4 gene 25 expression: MRNA secondary structure that enhances translational initiation. Journal of Molecular Biology, 288(3), 291-304. https://doi.org/10.1006/jmbi.1999.2695

Nou, X., \& Kadner, R. J. (2000). Adenosylcobalamin inhibits ribosome binding to btuB RNA. Proceedings of the National Academy of Sciences of the United States of America, 97(13), 7190-7195. https://doi.org/10.1073/pnas.130013897

Papenfort, K., Bouvier, M., Mika, F., Sharma, C. M., \& Vogel, J. (2010). Evidence for an autonomous 5 ' target recognition domain in an Hfq-associated small RNA. Proc Natl Acad Sci U S A, 107(47), 20435-20440. https://doi.org/10.1073/pnas.1009784107

Papenfort, K., Espinosa, E., Casadesus, J., \& Vogel, J. (2015). Small RNA-based feedforward loop with AND-gate logic regulates extrachromosomal DNA transfer in Salmonella. Proc Natl Acad Sci U S A, 112(34), E4772-81. https://doi.org/10.1073/pnas.1507825112

Paulus, M., Haslbeck, M., \& Watzele, M. (2004). RNA stem-loop enhanced expression of previously non-expressible genes. Nucleic Acids Res., 32(9), e78. https://doi.org/10.1093/nar/gnh076

Pedersen, S. (1984). Escherichia coli ribosomes translate in vivo with variable rate. The EMBO Journal, 3(12), 2895-2898.

Perdrizet, G. A., Artsimovitch, I., Furman, R., Sosnick, T. R., \& Pan, T. (2012). Transcriptional pausing coordinates folding of the aptamer domain and the expression platform of a riboswitch. Proceedings of the National Academy of Sciences of the United States of America, 109(9), 3323-3328. https://doi.org/10.1073/pnas.1113086109

Philippe, C., Eyermann, F., Benard, L., Portier, C., Ehresmann, B., \& Ehresmann, C. (1993). Ribosomal protein $\mathrm{S} 15$ from Escherichia coli modulates its own translation by trapping the ribosome on the mRNA initiation loading site. Proc. Natl. Acad. Sci. USA, 90(10), 4394-4398.

Pleij, C. W., Rietveld, K., \& Bosch, L. (1985). A new principle of RNA folding based on pseudoknotting. Nucleic Acids Research, 13(5), 1717-1731. https://doi.org/10.1093/nar/13.5.1717

Plotkin, J. B., \& Kudla, G. (2011). Synonymous but not the same: The causes and consequences of codon bias. Nature Reviews. Genetics, 12(1), 32-42. https://doi.org/10.1038/nrg2899

Pörschke, D. (1974). Thermodynamic and kinetic parameters of an oligonucleotide hairpin helix. Biophysical Chemistry, 1(5), 381-386. https://doi.org/10.1016/0301-4622(74)85008-8

Prevost, K., Salvail, H., Desnoyers, G., Jacques, J. F., Phaneuf, E., \& Massé, E. (2007). The small RNA RyhB activates the translation of shiA mRNA encoding a permease of shikimate, a compound involved in siderophore synthesis. Mol. Microbiol., 64, 1260-1273.

Proshkin, S., Rahmouni, A. R., Mironov, A., \& Nudler, E. (2010). Cooperation between translating ribosomes and RNA polymerase in transcription elongation. Science (New York, N.Y.), 328(5977), 504508. https://doi.org/10.1126/science.1184939

Qu, X., Wen, J. D., Lancaster, L., Noller, H. F., Bustamante, C., \& Tinoco, I. (2011). The ribosome 
uses two active mechanisms to unwind messenger RNA during translation. Nature, 475(7354), 118 121. https://doi.org/10.1038/nature10126

Quax, T. E. F., Claassens, N. J., Söll, D., \& van der Oost, J. (2015). Codon Bias as a Means to FineTune Gene Expression. Molecular Cell, 59(2), 149-161. https://doi.org/10.1016/j.molcel.2015.05.035

Reining, A., Nozinovic, S., Schlepckow, K., Buhr, F., Fürtig, B., \& Schwalbe, H. (2013). Three-state mechanism couples ligand and temperature sensing in riboswitches. Nature, 499(7458), 355-359. https://doi.org/10.1038/nature12378

Rieder, R., Lang, K., Graber, D., \& Micura, R. (2007). Ligand-induced folding of the adenosine deaminase A-riboswitch and implications on riboswitch translational control. Chembiochem: A European Journal of Chemical Biology, 8(8), 896-902. https://doi.org/10.1002/cbic.200700057

Romilly, C., Chevalier, C., Marzi, S., Masquida, B., Geissmann, T., Vandenesch, F., ... Romby, P. (2012). Loop-loop interactions involved in antisense regulation are processed by the endoribonuclease III in Staphylococcus aureus. RNA Biology, 9(12), 1461-1472. https://doi.org/10.4161/rna.22710

Romilly, C., Deindl, S., \& Wagner, E. G. H. (2019). The ribosomal protein S1-dependent standby site in tisB mRNA consists of a single-stranded region and a $5^{\prime}$ structure element. Proceedings of the National Academy of Sciences, 201904309. https://doi.org/10.1073/pnas.1904309116

Sarker, S., \& Oliver, D. (2002). Critical regions of secM that control its translation and secretion and promote secretion-specific secA regulation. Journal of Bacteriology, 184(9), 2360-2369. https://doi.org/10.1128/jb.184.9.2360-2369.2002

Scharff, L. B., Childs, L., Walther, D., \& Bock, R. (2011). Local Absence of Secondary Structure Permits Translation of mRNAs that Lack Ribosome-Binding Sites. PLoS Genetics, 7(6), e1002155. https://doi.org/10.1371/journal.pgen.1002155

Sørensen, M. A., Kurland, C. G., \& Pedersen, S. (1989). Codon usage determines translation rate in Escherichia coli. Journal of Molecular Biology, 207(2), 365-377. https://doi.org/10.1016/00222836(89)90260-x

Spedding, G., \& Draper, D. E. (1993). Allosteric mechanism for translational repression in the Escherichia coli alpha operon. Proceedings of the National Academy of Sciences of the United States of America, 90(10), 4399-4403. https://doi.org/10.1073/pnas.90.10.4399

Spencer, P. S., Siller, E., Anderson, J. F., \& Barral, J. M. (2012). Silent substitutions predictably alter translation elongation rates and protein folding efficiencies. Journal of Molecular Biology, 422(3), 328335. https://doi.org/10.1016/j.jmb.2012.06.010

Sterk, M., Romilly, C., \& Wagner, E. G. H. (2018). Unstructured 5'-tails act through ribosome standby to override inhibitory structure at ribosome binding sites. Nucleic Acids Research, 46(8), 4188-4199. https://doi.org/10.1093/nar/gky073

Suess, B., Fink, B., Berens, C., Stentz, R., \& Hillen, W. (2004). A theophylline responsive riboswitch based on helix slipping controls gene expression in vivo. Nucleic Acids Research, 32(4), 1610-1614. https://doi.org/10.1093/nar/gkh321

Takyar, S., Hickerson, R. P., \& Noller, H. F. (2005). MRNA helicase activity of the ribosome. Cell, 120(1), 49-58. https://doi.org/10.1016/j.cell.2004.11.042 
Tsuchihashi, Z., \& Kornberg, A. (1990). Translational frameshifting generates the gamma subunit of DNA polymerase III holoenzyme. Proceedings of the National Academy of Sciences of the United States of America, 87(7), 2516-2520. https://doi.org/10.1073/pnas.87.7.2516

Tucker, B. J., \& Breaker, R. R. (2005). Riboswitches as versatile gene control elements. Curr. Opin. Struct. Biol., 15(3), 342-348. https://doi.org/10.1016/j.sbi.2005.05.003

Tuller, T., Waldman, Y. Y., Kupiec, M., \& Ruppin, E. (2010). Translation efficiency is determined by both codon bias and folding energy. Proceedings of the National Academy of Sciences of the United States of America, 107(8), 3645-3650. https://doi.org/10.1073/pnas.0909910107

Varenne, S., Buc, J., Lloubes, R., \& Lazdunski, C. (1984). Translation is a non-uniform process. Effect of tRNA availability on the rate of elongation of nascent polypeptide chains. Journal of Molecular Biology, 180(3), 549-576. https://doi.org/10.1016/0022-2836(84)90027-5

Wagner, E. G., Altuvia, S., \& Romby, P. (2002). Antisense RNAs in bacteria and their genetic elements. Adv. Genet., 46, 361-398.

Weiss, R. B., Dunn, D. M., Atkins, J. F., \& Gesteland, R. F. (1987). Slippery runs, shifty stops, backward steps, and forward hops: $-2,-1,+1,+2,+5$, and +6 ribosomal frameshifting. Cold Spring Harb. Symp. Quant. Biol., 52, 687-693.

Wen, J. D., Lancaster, L., Hodges, C., Zeri, A. C., Yoshimura, S. H., Noller, H. F., .. Tinoco, I. (2008). Following translation by single ribosomes one codon at a time. Nature, 452(7187), 598-603. https://doi.org/10.1038/nature06716

Winkler, W., Nahvi, A., \& Breaker, R. R. (2002). Thiamine derivatives bind messenger RNAs directly to regulate bacterial gene expression. Nature, 419(6910), 952-956. https://doi.org/10.1038/nature01145

Wulczyn, F. G., Bolker, M., \& Kahmann, R. (1989). Translation of the bacteriophage Mu mom gene is positively regulated by the phage com gene product. Cell, 57(7), 1201-1210.

Wulczyn, F. G., \& Kahmann, R. (1991). Translational stimulation: RNA sequence and structure requirements for binding of Com protein. Cell, 65(2), 259-269. https://doi.org/10.1016/00928674(91)90160-z

Yamamoto, H., Wittek, D., Gupta, R., Qin, B., Ueda, T., Krause, R., ... Nierhaus, K. H. (2016). 70Sscanning initiation is a novel and frequent initiation mode of ribosomal translation in bacteria. Proc Natl Acad Sci U S A, 113(9), E1180-9. https://doi.org/10.1073/pnas.1524554113

Yan, S., Wen, J.-D., Bustamante, C., \& Tinoco, I. (2015). Ribosome excursions during mRNA translocation mediate broad branching of frameshift pathways. Cell, 160(5), 870-881. https://doi.org/10.1016/j.cell.2015.02.003

Yanofsky, C. (2007). RNA-based regulation of genes of tryptophan synthesis and degradation, in bacteria. RNA, 13(8), 1141-1154. https://doi.org/10.1261/rna.620507

Zhang, G., Hubalewska, M., \& Ignatova, Z. (2009). Transient ribosomal attenuation coordinates protein synthesis and co-translational folding. Nature Structural \& Molecular Biology, 16(3), 274-280. https://doi.org/10.1038/nsmb.1554

Zhang, G., \& Ignatova, Z. (2011). Folding at the birth of the nascent chain: Coordinating translation 
with co-translational folding. Current Opinion in Structural Biology, 21(1), 25-31.

937 https://doi.org/10.1016/j.sbi.2010.10.008

938 Zhang, Y., Burkhardt, D. H., Rouskin, S., Li, G.-W., Weissman, J. S., \& Gross, C. A. (2018). A Stress 939 Response that Monitors and Regulates mRNA Structure Is Central to Cold Shock Adaptation. 940 Molecular Cell, 70(2), 274-286.e7. https://doi.org/10.1016/j.molcel.2018.02.035

941 Zhang, Y., \& Gladyshev, V. N. (2005). An algorithm for identification of bacterial selenocysteine 942 insertion sequence elements and selenoprotein genes. Bioinformatics (Oxford, England), 21(11), 2580943 2589. https://doi.org/10.1093/bioinformatics/bti400

944 Zinoni, F., Birkmann, A., Leinfelder, W., \& Böck, A. (1987). Cotranslational insertion of 945 selenocysteine into formate dehydrogenase from Escherichia coli directed by a UGA codon. 946 Proceedings of the National Academy of Sciences of the United States of America, 84(10), 3156-3160. 947 https://doi.org/10.1073/pnas.84.10.3156

948 Zinoni, F., Heider, J., \& Böck, A. (1990). Features of the formate dehydrogenase mRNA necessary for 949 decoding of the UGA codon as selenocysteine. Proceedings of the National Academy of Sciences of the 950 United States of America, 87(12), 4660-4664. https://doi.org/10.1073/pnas.87.12.4660

951 